University of Louisville

ThinkIR: The University of Louisville's Institutional Repository

Electronic Theses and Dissertations

$5-2013$

\title{
"Two machines similarly constructed" : humanity between apes and clones.
}

Emily Regina Freund

University of Louisville

Follow this and additional works at: https://ir.library.louisville.edu/etd

\section{Recommended Citation}

Freund, Emily Regina, "'Two machines similarly constructed" : humanity between apes and clones."

(2013). Electronic Theses and Dissertations. Paper 459.

https://doi.org/10.18297/etd/459

This Master's Thesis is brought to you for free and open access by ThinkIR: The University of Louisville's Institutional Repository. It has been accepted for inclusion in Electronic Theses and Dissertations by an authorized administrator of ThinkIR: The University of Louisville's Institutional Repository. This title appears here courtesy of the author, who has retained all other copyrights. For more information, please contact thinkir@louisville.edu. 


\title{
“TWO MACHINES SIMILARLY CONSTRUCTED":
} HUMANITY BETWEEN APES AND CLONES

\author{
By \\ Emily Regina Freund \\ B.A. Indiana University, 2003

\begin{abstract}
A Thesis
Submitted to the Faculty of the

College of Arts and Sciences of the University of Louisville in Partial Fulfillment of the Requirements for the Degree of
\end{abstract}

Master of Arts

Department of English University of Louisville

Louisville, Kentucky

May 2013 
Copyright 2013 by Emily Regina Freund

All rights reserved 

“TWO MACHINES SIMILARLY CONSTRUCTED”:

HUMANITY BETWEEN APES AND CLONES

\author{
By \\ Emily Regina Freund \\ B.A. Indiana University, 2003
}

A Thesis Approved on

April 17, 2013

By the following Thesis Committee:

Dr. Glynis Ridley, English, Thesis Director

Dr. Aaron Jaffe, English

Dr. Avery Kolers, Philosophy 


\section{DEDICATION}

This thesis is dedicated to my parents

Mr. Kevin Gerard Freund

and

Mrs. Cheryl Ann Freund

my first readers. 


\section{ACKNOWLEDGEMENTS}

I would like to thank my thesis director, Dr. Glynis Ridley, for her endless support, guidance, and sense of humor. I also extend my thanks to the committee members, Dr. Aaron Jaffe and Dr. Avery Kolers, for their interest in reading and commenting on my project. Many thanks to my family - my parents, Kevin and Cheryl, my sister Bernadette, and brother-in-law Jim, for their support and encouragement throughout all of my endeavors, academic or otherwise. Jag vill också framföra mitt tack till mina vänner i Sverige: Ann-Marie, Claes, David och Kathrin. Och till Gustav, min favoritmänniska, tack för all din kärlek och allt ditt stöd under vår gemensamma färd. 


\section{ABSTRACT \\ “TWO MACHINES SIMILARLY CONSTRUCTED”: HUMANITY BETWEEN APES AND CLONES \\ Emily Regina Freund}

April 17, 2013

“Two Machines Similarly Constructed”: Humanity Between Apes and Clones explores the development of scientific taxonomies of difference and the proliferation and evolution of the definition of the "human." A focus on Enlightenment naturalists' texts and images of apes reveals how these scientists defined the human "difference" and lends to Michel Foucault's archaeology of the invention of "man." This establishes the concept of a classifying discourse and argues that a narrative of human exceptionalism pervaded subsequent ideas of progress and civilization. Analyses of two texts, Mary Shelley's Frankenstein and Kazuo Ishiguro's Never Let Me Go, develop a discussion of how the authors present non-humans and clones that complicate the definition of the "human" and incorporate resistance to the classifying discourse's singular way of understanding the natural order. An investigation of the development of Homo sapiens's "difference" locates examples of classifying humans and non-humans; this project examines how authors and scientists resist strict exclusions and classifications in a larger, more allencompassing consideration of the "human condition." 


\section{TABLE OF CONTENTS}

PAGE

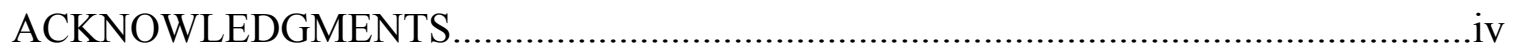

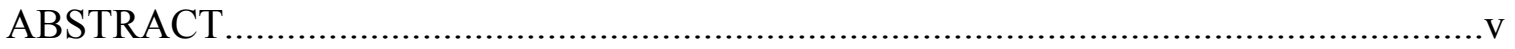

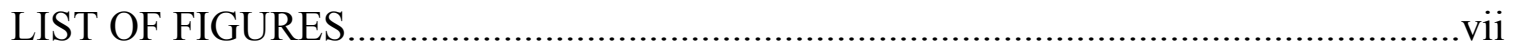

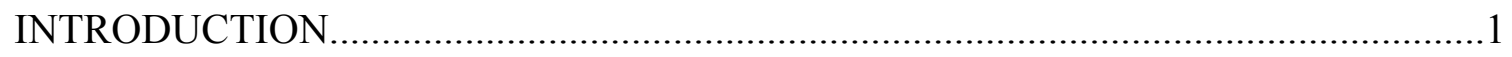

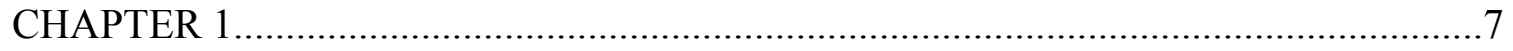

Linking the Chain: The Classifying Discourse..................................................

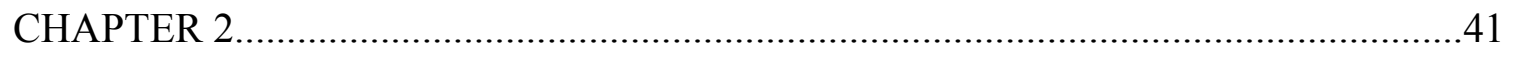

The Barriers Between: Frankenstein's Enlightened Non-Human............................41

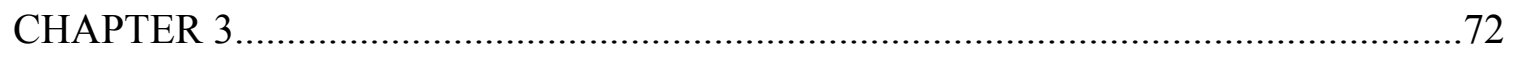

The View from the Other Side: Never Let Me Go's Clones......................................72

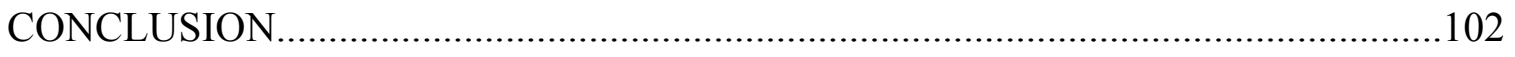

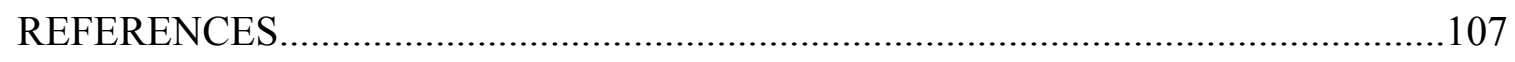

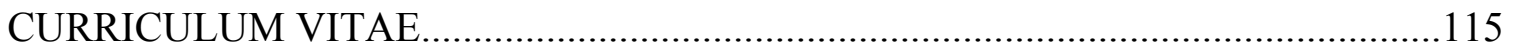




\section{LIST OF FIGURES}

FIGURE

PAGE

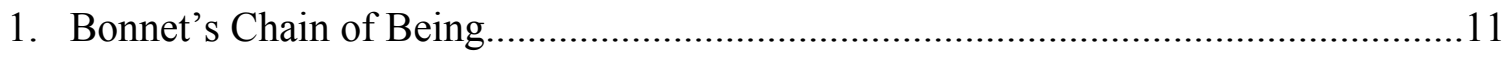

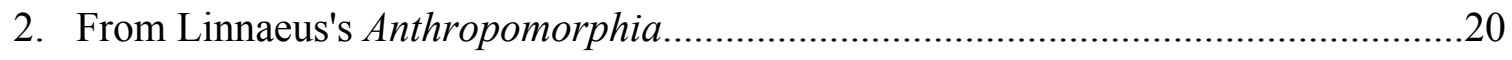

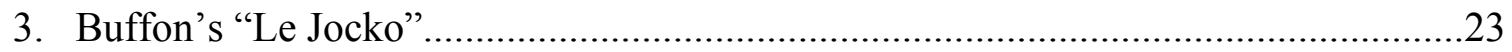

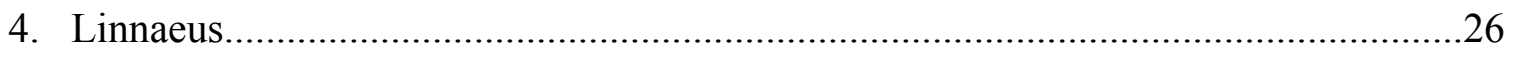

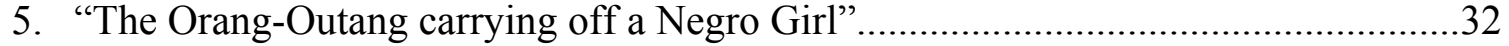

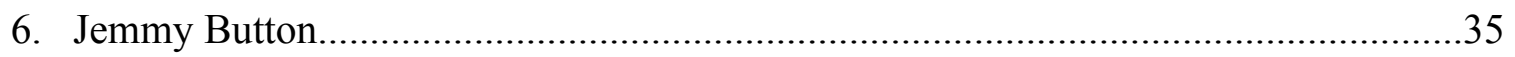

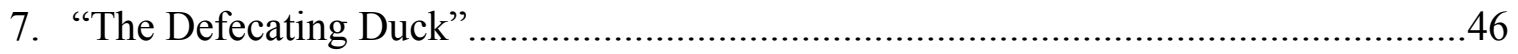

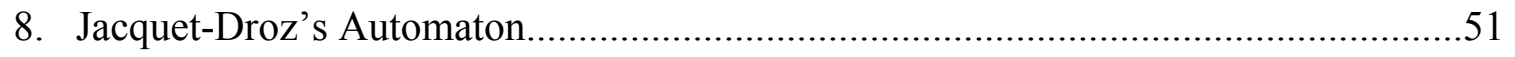

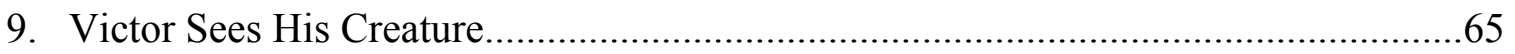

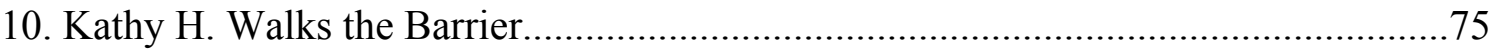

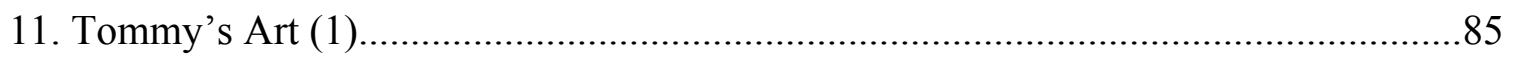

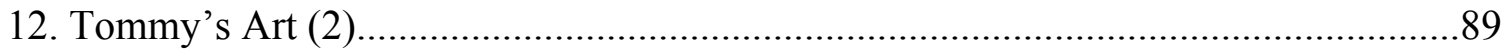

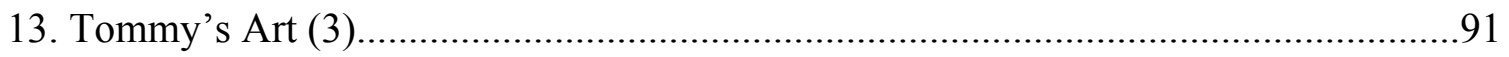




\section{INTRODUCTION}

"The ape and the human body are two machines similarly constructed, and necessarily move nearly in the same manner. But parity is not imitation. The one depends on matter, and the other on mind."

- George-Louis Leclerc, Comte de Buffon, L'Histoire Naturelle (1766)

In a 2006 interview, when Kazuo Ishiguro responded to a question regarding his choice to depict the lives of clones in his 2005 novel, Never Let Me Go, he answered that the clones were a metaphor "for something very simple - it sounds rather grand - but, a metaphor for the human condition" (Wong and Crummett 215). The clones, re-named "students" by their human instructors, live half-lives within the confines of a boarding school and small compounds, learn to "be" human through studies in the humanities, and accept their fates of organ donation and death. Never Let Me Go's narrator, Kathy H., leads readers through experiences and reflections that seem inherently human, despite many of the human characters' misgivings. The difference between the clones and humans is, as one of their teachers, Miss Emily, recounts, that humans are not sure if the clones "had souls at all" (260). Without souls, the humans feel as though they are justified in using the clones for their more superior existence.

This question of the "soul" making the "human" is hardly a new one. Searches for evidence of the human soul, and the belief that an exclusively human soul marks the species as divinely inspired, have prevailed throughout history. As Foucault indicates in The Order of Things, when humans began classifying and defining humans and nonhumans within scientific systems, the question of what it means to be "human" became a 
major determining factor in ascribing developmental status, care, and concern for populations seen as outside the purview of Western European men. When this "classifying discourse" became the dominant mode of scientific determination, its methods of naming and defining species along the Chain of Being established barriers between animalistic, non-human beings and civilized, intelligent, and godly Homo sapiens. These barriers extend into contemporary writing, but the fences have recently started to disintegrate. Although Enlightenment naturalists and philosophers recognized and documented physiological similarities between humans and animals, especially apes, in order to ensure that humans remained superior, they located differences that ensconce humans just below the divine angels and Creator but above all other living creatures. Naturalists were interested in linking the Great Chain of Being, but just as philosophers and theologians had argued for centuries, the Biblical mythos that placed humans directly under and within the canopy of the divine prevailed. Enlightenment-era naturalists were just as convinced of Aristotle's belief that what separated man from the rest of animate creation was the human rational soul and connection to the angels.

In the eighteenth century, Europe entered into a new period of intellectualism and scientific discovery. Industrial and technological advances, and the rise of the middle and leisure class that accompanied them, signaled a shift in concerns and priorities. Scientific inquiry became an honorable pursuit, and scientists, themselves a new professional distinction, began searching for empirical ways to understand both their world and their place within it. Taxonomic and ontological debates within the lecture halls spread on to travelers, writers, and the reading public; consumption and widening readerships led to the proliferation of encyclopedic texts and volumes on plants and animals. Most notably, 
Linnaeus's many editions of the Systema Naturae and Buffon's Histoire Naturelle presented stunning engravings and illustrations of the natural world, both the known and common and, more interestingly, the strange and foreign. This was a time of European empire building, and expansion into Africa and Asia led to new discoveries of animals and native populations. While the growing bourgeoisie began participating in scientific and ontological conversations, the changing ideology behind power structures began to influence ideas about civilization and progress.

The power relations, and the power of naming the "human" through scientific textual control, connect with the ideology of progress and control of the body. As classifications and taxonomic nomenclature based on appearance determined a being's place on the scale of development, we can see how perceived intelligences were subject to a specific discourse's epistemic tenets. The classifying discourse dominates over all other ways of knowing, so beings that may not adhere to these organizations will appear more Other and separate from those already interpellated into the given ideology. By investigating the development of this classifying discourse and locating early examples of separating "human" from "non-human," we can identify anxieties and social ideologies that led humans to consider themselves superior. We can also examine how authors and scientists began to resist these strict exclusions and classifications in a larger, more allencompassing consideration of "the human condition" that did not necessarily apply to only those named Homo sapiens. In the following chapters, I will conduct this investigation, and examine Western thought's foundations of classifying the "human" in terms of its definition and creation of a taxonomic, classified human, Homo sapiens. This will lead to an examination of two texts, Frankenstein and Never Let Me Go, that serve as 
markers for questioning the discourse's strict definitions of the "human" and expanding the consideration of human nature into new ways of knowing. These texts open new discourses that question human exceptionalism, but also reveal human anxieties toward dismantling the barrier between "us" and "them."

Chapter 1 focuses on Enlightenment naturalists' texts and what Foucault refers to as the "invention of "man," with an examination of the historical development of the classifying discourse, including naturalists' considerations of the human difference and soul. Naturalists determined that humans were subject to inquiry as animals, but they still established attributes and qualifications, such as the intellect and the soul, which would continue the narrative of human exceptionalism. Once I have established the discourse's definitions of what can be classified as "human" and identified the ideas of progress and civilization that it created, I will move into a discussion of how cultural engagement with those ideas often incorporated resistance to a singular way of understanding human nature. Chapter 2 will consider how Mary Shelley's famous text, Frankenstein, works within and yet critiques the dominant discourse. The creature is, for all corporeal means, human, yet his appearance defines him as a "monster" and denies him human status, instead marking him as a new species. Despite his non-human definition, the creature is thoughtful and intelligent, and his reading and education is decidedly "humanistic"; his narrative attempts to assert his own mastery of the discourse. However, humans rely on their own powers of definition, and Victor's gaze determines the being to be non-human and refuses the creature's request for social interaction. I will argue that Shelley's understanding of the human condition requires multiple "ways of knowing," including the feminine discourse of reproduction. The creature cannot be defined under a singular 
classifying discourse and is only able to be classified as an aberration, while perhaps multiplicities of knowing could allow his entry into the human family.

In Never Let Me Go, the focus of Chapter 3, Ishiguro investigates what it means to be human through the point of view of Kathy H., one of many clones artificially created to be an organ donor for human beings. The clones are, for all appearances, human, and Ishiguro complicates the question of human nature by moving the conversation inside the body and focuses on what we feel rather than what we see. Rather than a concern with retaining a species through reproduction, as Frankenstein's creature exhibits, the clones see themselves as "complete" when taken apart, donating their organs to humans. Yet Kathy H.'s memoir gives her direct control of the text and her story gives a power and humanity to her narrative that the creature's narrative, translated through a human voice, cannot. Readers do not "hear" the creature's voice as they hear Kathy's, and just as naturalists control the narrative and images of native peoples, we are subject to the frame that contains the creature's story. We understand and empathize with Kathy's emotions, and as the human characters show, allow a tentative "human" status, although the novel vacillates between accepting the clones as soulful humans or imitative, non-human copies.

As Ishiguro states, Never Let Me Go explores "what it means to be a human being" (Hunnewell). An investigation of Enlightenment-era definitions and classifications of the "human" versus other animals will lend to considerations of how Frankenstein and Never Let Me Go address what human "is" by exploring examples of what we have deemed "is not." We can look forward to how Homo sapiens will incorporate other ways of knowing 
and considering life after the barrier crumbles, and how, as Foucault indicates, "man" will no longer exist as a being separated by a fence of human nature. 


\section{CHAPTER 1}

\section{LINKING THE CHAIN: THE CLASSIFYING DISCOURSE}

In 1699, when the British physician Edward Tyson dissected a young chimpanzee that had died during its transportation to England, he noted what he perceived to be an eerie similarity between known species of apes and man. Tyson's text, Orang-Outang, sive Homo Sylvestris. Or the Anatomy of a Pygmie compared with that of a Monkey, an Ape and a Man, is noteworthy because in addition to publishing descriptions and detailed images of a chimpanzee's dissection, his work also accounted for an outright statement of the relationship between humans and chimps (Ritvo, "Border Troubles" 483). Similar to Tyson's relationships, Linnaeus's Systema Naturae included humans as a part of the animal kingdom that were classified together with apes in the genus Homo, as Homo sapiens and Homo troglodytes. In these texts, exotic apes are often depicted as humanlike, gentle, modest, and strikingly intelligent; and although many artists and authors did not have direct experience or access to apes, the reproduction and repetition of certain aspects present a narrative of both similarity and difference between humans and apes.

Although concerns eventually shifted from defining a species that looks so seemingly (and later, genetically) similar to Homo sapiens, the rise of classification, taxonomic definition, and specifying the links of the Great Chain of Being extended far beyond the difference between an ape and a human. Naturalists looked for what makes 
the human animal so different, and so seemingly special, from all other creatures. Ideas forwarded by Tyson, Linnaeus, Buffon, and Monboddo, in addition to numerous others, attempted to draw a distinction between humans and animals, especially in light of René Descartes's and Charles Bonnet's ruminations on difference and human exceptionalism. After naturalists more or less acknowledged an ape-human resemblance, they began to consider exactly how this resemblance came to be. This is why the subsequent conversation is intriguing, for the naturalists' tendencies to document a similarity to apes is all the more interesting when considered against the resistance to the relationship between "lesser," "primitive" native peoples and Europeans. As Londa Schiebinger notes, "early accounts of anthropoid apes pouring into Europe in this period often told more about European customs than about the natural habits of apes" (76). The stories of how these male naturalists classified "apes" can unearth how they also classified their own species. Appearances often guided naturalists' classification systems, and the narrative of similarities eventually became so exacting as to become descriptions of difference. This discourse, a way of knowing based on classifying and naming, became the dominant force behind defining the "human," and, consequently, assigning or denying humanity to those considered more "animal" than human. The classifying discourse defined what it means to be a human being, and wrote the narrative on human nature that emphasized the differences, the barrier, between "us" and "them" - including classifying thought, reason, and the soul strictly to Homo sapiens. 


\section{LiNKS TO HUMAN DifFERENCE}

For centuries, pre-Enlightenment philosophers and theologians weighed in on the difference between humans and non-humans, and aimed to specify what attributes delineated the barrier. As Harriet Ritvo notes, the Biblical creation myth persisted as one of the most prevailing ideas, proclaiming that humans alone enjoyed the distinction of a god-like resemblance ("Border Trouble" 482). In many cases, naturalists aimed to classify humans "according to pre-existing habits of thought and by religious concerns over mankind's proximity to the divine" (Douthwaite 69). Angels had reason, and, as Londa Schiebinger explains, this reason "raised humans to a point midway between angels and beasts. Humans shared reason and intellect with the angels, body and senses with the animals" (81). In the early seventeenth century, René Descartes continued the conversation about what defined humans as so different from other animals; one of the most-often used descriptions for human being's exceptionalism involves Descartes's assertion that bodies, both human and non-human, work like "machines." As Geneviève Rodis-Lewis explains in "Limitations of the Mechanical Model in the Cartesian Conception of the Organism," Descartes revised, or at least clarified his position, on Aristotle's formulation of nature as the ultimate model for man-made creations. She quotes Descartes, noting, "As art imitates nature and men are capable of making various automata which move but have no thought, it seems consistent with reason that nature produce its own automata, though far superior to our artefacts" (qtd. in Rodis-Lewis 159). Descartes means that because human beings can create working machines in imitation of "natural" movement, nature itself must make its own machines, namely, animals. Lest we be unconvinced, "'I consider,' says Descartes, 'the human body to be a machine,' 
comparable to a clock" (Rodis-Lewis 163). Animals are automata, created by nature; humans are also automata, but are marked with a form of Aristotle's rational soul. However, although lower animals do not have souls, they possess an adaptation that reveals a type of "feeling," which Descartes identifies as passions (Rodis-Lewis 162). But, if humans are animals, how do they have automaton bodies and also carry rational souls without clear separations?

Descartes explains the soul's material composition within the brain, so, although the soul is what marks an animal "human," the location of consciousness is in reality part of the machine. As Jacques Roger clarifies, "the motion of spirits was transmitted directly to the 'pineal gland' situated in the middle of the brain, which was the seat of the soul" (250). The human has a unified mind and body, composed together as a whole. RodisLewis quotes M. Gueroult's explanation of Descartes's mind-body relation: “this machine belongs to the soul with which it is associated...This conception of the indivisibility of the organism, which is uniquely ascribed to an actually animated organism..hence ascribed to man alone" (qtd. in Rodis-Lewis 162). Humans can function without certain organs, but the mind and body work together, as a set of irreducible working parts. Descartes sees that the body must retain its composition to remain unified with its soul, so that the soul "leaves it [the body] altogether when the assemblage of its organs is dissolved" (qtd. in Rodis-Lewis 163). If the human body did not contain a soul, the body would cease to be human; for the body's organs can function without this, as we see with lower animals. As machines, animals behave instinctually, often confused with intellect, and while humans have these animal instincts and passions, their rational souls can negate or cancel their innate reactions. However, the question of "instinct" becomes a 
sticking point, for if humans are instinctual animals, their divinely appointed position on the Chain of Being is in jeopardy. As Stefani Engelstein notes, when philosophers began to look to the body for proof of a soul, this "vaunted position" between the lower animals below and the angels above was on shaky ground (179).

Although the soul remained a major indicator of human status, many naturalists and philosophers focused on defining the human animal in relation to other living things. Aristotle and Plato had stipulated that all life could be identified or ranked in a scale of nature, a scala naturae (Brandt \& Reyna 428). This idea was further developed by

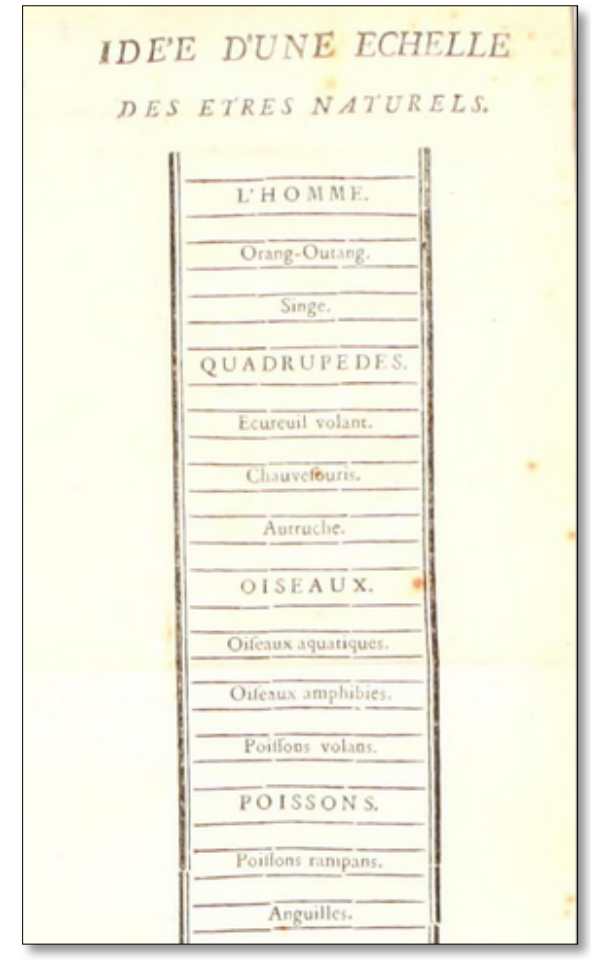

FIG. 1. Bonnet's Chain of Being. From Traité D'insectologie. Vol. 1. Paris: Chez Durand, 1745. philosophers of the medieval period, where they introduced the concept of this ladder as divine, with God occupying the top tier, followed by angels, humans, animals, plants, and minerals, with distinct lines or barriers between each. During the Enlightenment period, naturalists began to think about how this gradation could link together and form a "Chain of Being" to recognize not only the similarities linking different groups together, but also the differences that defined them. Most importantly, naturalists were concerned with identifying where humans could expect to fit on this

Chain, and especially questioned the possibility for a direct relationship to apes in a way that might mark humans as less-divinely inspired than previously conceived. 
In 1745, the Swiss naturalist Charles Bonnet published Traité d'insectologie, and included his conception of the scala naturae (Fig.1). In it, he identifies humans and animals by specific type, and discerns the levels they occupy based on the similarity of their exterior appearances and functions (Anderson 49). According to Lorin Anderson's analysis, Bonnet forwarded an unchanging hierarchical organization to life, and everything, from the human being to the rock, occupied a place in an "all-embracing continuum" (46). In fact, the only being not included in this Chain is the Creator, who linked all together and related them by different degrees of similarity: "The series of these degrees composes the Universal Chain. It unites all beings, links the whole world, embraces all spheres. A single Being alone is outside of this chain, and that is He who made it" (qtd. in Anderson 46). Bonnet believed that all things, living and inanimate, were created by God in their current form, and all things to be were already conceived in females, to be revealed in future generations. However, Bonnet was also interested in nomenclature, and commented on the development of a naming system outside of nature suited to humans' own needs for order: "If nothing is severed in nature, it is evident that our classifications are not its own. Those that we form are purely nominal, and we should regard them as means relative to our needs and to the boundaries of our knowledge" (qtd. in Anderson 46). The lasting legacy of this Chain of Being remains the association of apes and humans, and although not on the same hierarchical "level" or "link," Bonnet identified human beings as part of the natural order and subject to classification. So, although non-human animals were lower on the Chain, they were not severed or disconnected from humans, who were themselves not superior to scientific inquiry. But 
those most subject to inquiry, at least in regard to studies of the bridge between the ape and the human, were non-Western, indigenous peoples.

\section{NAMing THE HUMAN}

Apart from desiring descriptions and images of exotic animals and peoples, Europeans continued to raise questions of "humanity" and what it means to be human as either apart from or in concert with animals. While Cartesians argued for animals as mechanistic automata and stipulated that the mind-body relationship and "soul" was the exclusive provenance of humans, John Locke held that both human and non-human animals could feel pain and were similar in many respects. In the context of nomenclature and relationships between species, Locke argued that classification necessarily required a subject position, and that “'man' was an arbitrary label, given or withheld according to the observer's eye alone" (Douthwaite 14). Eighteenth-century naturalists became increasingly important purveyors of knowledge and impressions about so-called "exotic" animals. In the case of apes and "primitive" native humans, their encyclopedias and natural histories controlled the narrative, discourse, and observations of not only physical characteristics and intellects, but also who qualified as a "human" link on the Chain of Being.

When Western explorers returned from their travels, they brought fabulous stories and "specimens" back with them - this period, especially into the mid-nineteenth century, pitted curiosities and artifacts with tableaus of native peoples, often staged to produce a 
certain narrative of primitive and undeveloped ape-human hybrids ${ }^{1}$. Naturalists assumed that the native peoples and apes were closely connected on the Chain, and that native peoples were, at first discovery, closer to apes. The continued interest in classification and the Great Chain of Being denied these native peoples a status equal to that of their European counterparts. The "civilized" considered the "primitive" peoples the link that connected the Chain of apes and humans, with these native populations bridging the gap between Europeans and lower animals. "Civilization" influenced European ideals of beauty, form, and language, and European naturalists assumed that people who did not "look" like those in power must necessarily be different, attributed to their inability to adhere to normative modes of presentation and behavior. This Othering of native peoples allowed Europeans to distance themselves from humans in landscapes and situations foreign to theirs, but also gave the civilized a type of narrative power over the people, prioritizing their taxonomic naming methods as the most authoritative, compelling, and persuasive. The natives' subjection reveals the Western anxiety of locating humans that they saw as blurring the line between the human and animal. This anxiety contributed to motivations for Western civilizing missions intended to "raise" lower humans back to a closer resemblance to their Western fellow-creatures. The images of difference and animalistic characteristics became the evidence of a need - Europeans read these images as proof that not only did the native populations need to rise to European development, but that the natives wanted to be like Europeans. This encouraged ideas of a Western duty to attempt to "civilize" these peoples, spreading not only their worldviews but also their religions and practices. When the discourse of progress extends to classification,

\footnotetext{
${ }^{1}$ Many displays and spectacles attempted to bill authenticity as their selling points, and built staged native villages complete with humans who were "life-pictures" of the animalistic and primitive populations. These were often billed as educational for the general public (Coombes 86).
} 
observation, a civilizing mission, and power dynamics, we can begin to trace the relationship and power of prevailing words and images in what Michel Foucault calls the "disciplinary space of natural beings" (qtd. in Douthwaite 15).

The taxonomic nomenclature that we know today did not appear overnight; rather, a long chain of naturalists weighed in on how to identify and classify plants and animals on a scale of development. This began at a turning point in scientific "history," one that introduces what Foucault terms as the "Classical" age of natural history. In his The Order of Things: An Archaeology of the Human Sciences, Foucault interprets the nascency, or, as he puts it, archaeology, of the natural sciences during this time. He argues that nomenclature and classification became possible at this point, when Bonnet declared that minute differences could be seen as similarities between species. But, if genera must be further defined into species, these similarities must shift back into being considered as differences, and what those differences could tell us about how we should see them on the Chain: "For taxonomy to be possible...nature must be truly continuous, and in all its plenitude...classification requires the principle of the smallest possible difference between things" (Foucault, Order 159). Natural history, to Foucault, was a new field or "space" opened up during the Enlightenment, where men were able to use new technologies and languages to analyze the living world around them and contemplate where human beings were in relation to others. However, when a specific method arrived, naturalists were expected to remain within the confines of their discourse community: "Natural history did not become possible because men looked harder and more closely. One might say, strictly speaking, that the Classical age used its ingenuity, if not to see as little as possible, at least to restrict deliberately the area of its experience" (Order 132). However, 
Foucault's archaeology of natural history is problematic as he characterizes this Classical age as a rather abrupt shift. A new language was developing, and living things needed to be defined within it. Despite the problematic historical portrait, Foucault's analysis is valuable when considering how a new type of "knowing" was emerging, and this knowledge asserted its dominance by creating a new way of talking about and relating animals and humans together on the Great Chain. Foucault says that this description opens a space "anticipating the possibility of naming; it is the possibility of seeing what one will be able to say" (Order 130). Naming became synonymous with a place under God's wide umbrella of creation, and taxonomy enabled naturalists to open a dialogue about what makes a "human" human being.

But how did this new way of knowing, this Classical age, come about? How did Linnaean nomenclature, organization, and representation become the dominant discourse of natural history? When Systema Naturae was first published in 1735, many adherents and naturalists praised Linnaeus's new way of ordering nature, claiming that his system could bring legitimacy to their field, and also reaffirm that human beings were the "highest" of the living on earth (Ritvo, Platypus 13). However, many naturalists, most notably Georges-Louis Leclerc, Comte de Buffon, expressed opposition to Linnaeus's new system of ordering the animal kingdom. In the words of Buffon, filtered through translator Oliver Goldsmith, nature lives "in contradiction to our denominations and characters, and amazes more by her exceptions than by her laws" (qtd. in Ritvo, Platypus 23). When Linnaean binomial nomenclature was separated from the taxonomical classification system, it was seen as more promising because it replaced a cacophony of names; his nomenclature brought order to a divided and disorganized way of knowing, 
and unified natural history within a certain naming system (Platypus 52). But taxonomy and nomenclature were also ensconced in a tradition of representation, and the lasting debate revolved around classification based on either an animal's resemblance to each other or to their own inner natures.

Contrary to the impression Foucault leaves in The Order of Things, seventeenth and eighteenth-century naturalists, scientists, and philosophers still believed many of the theories or assertions of "man" and their exceptional minds, rather than strictly adhering to classifications based only on external features. In the late 1600 s, John Locke pointed to difficulties in categorizing "creatures" that are externally like a man, but have different senses, such as feral children: "there are naturals amongst us that have perfectly our shape, but want reason, and some of them language too" (qtd. in Douthwaite 14). For Locke, as well as Buffon and the Scottish judge James Burnett, Lord Monboddo, external form mattered, but language and intellect were also a chief indicator of human status. Foucault somewhat erroneously characterizes the shift from "similitude" to "difference" in the naturalists' tradition as an immediate and unanimous movement. Julia Douthwaite clarifies Foucault's argument and explains that the movement, while not instantaneous, did transition from value-laden qualities of "intellect" to external characteristics. This was an attempt for scientists to avoid "arbitrary" labels and social and cultural conventions, because the reliance on an animal's outward appearance to link and classify standardized methods across languages and cultures (14). However, Foucault's focus on the Chain, on the "inevitability of the connections with all the successive degrees of a series" (Order 55), emphasizes similarity leading to difference, and might help us to understand the proliferation of artistic representation and images within eighteenth- 
century naturalists' works. Engravings produced for natural histories by Linnaeus, Buffon, and Diderot and D'Alembert's Encylopédie often seem to be highlighting or referencing an animal's relation to people, and "often construct[ed] formal categories that echoed the anthropocentric and sentimental" (Ritvo, Platypus 39). This might seem slightly contradictory when considering how naturalists attempted to systematize or formalize the links in the Great Chain. When we investigate how naturalists such as Linnaeus and Buffon classified humans within the animal kingdom, we must also consider the representations that they created to emphasize the qualities and traits that they found persuasive towards their claims of human differences that retained divisions between humans and non-humans.

When we see how these representations seem to foreground a certain way of knowing a human or, in this study, an ape, we can begin to link the tendencies of narrative power to the control of how humans were perceived. Being able to use classifications and different names for human beings implied a hierarchy, Foucault's “smallest differences," and, according to Ritvo, "racial groups were routinely distinguished according to their degree of civilization" (Platypus 122). The power of naming a human as Homo sapiens with Europeans or as another, perhaps lower, species of human, closer to apes, conveyed a message of difference and separation between the observed and observer. This difference amounted to power, for if one has named and defined something, one can claim a type of power over treatment. Humans who were unequal to one another invited claims of necessary care and civilization. As Ritvo says, "Naming constituted a strong, if metaphoric, claim to possession, not only of the newly christened species, but by implication of its native territory" (Platypus 61). But how did 
naturalists distinguish between humans and apes, and how did this translate to a power relation? If we wish to understand how naturalists linked the Chain towards the "human," we must begin with one link and progress to the other. Apes, in many ways, looked like humans, and so naturalists' descriptions often focused on how they are different from humans - the classifying discourse defined features of apes in terms of how they were not human. In accordance with Foucault, the differences often defined the species, and by defining the "ape," we can see how naturalists defined and created the "human."

\section{HUMAN OR APE?}

When the Swedish naturalist Linnaeus set out to link humans to other animals on the Chain of Being, he invoked the divine right conferred by God, this time with Linnaeus as the "Second Adam," naming all of God's creatures according to their true names. Linnaeus stipulated that an animal's appearance helps define its status, and that the "task of natural history was to establish a hierarchy of species based on eternal, intrinsic characteristics" (Douthwaite 15). Although classifications might change based on new discoveries, Linnaeus believed that species were fixed and unchanged from God's first creation. In the first edition of his Systema Naturae, published in 1735, Linnaeus defined the genus Anthropomorphia as a general category for creatures that were either human or human-like (Douthwaite 16). As subsequent editions were published, increased complexity defined humans within the specific Homo genus, but the naturalist remained convinced that there were several human species.

In 1758, Linnaeus coined a new class, Mammalia. This family, while seemingly obvious to us today, was groundbreaking because it was the first systematic grouping of 
humans with other vertebrates such as apes, whales, and cows (Schiebinger 5). In Systema Naturae, Linnaeus lays out how he includes humans as part of the animal kingdom, and classified humans together with the "human-like" chimpanzee in the genus Homo, as Homo sapiens, and the unconfirmed but still named Homo troglodytes. As Ritvo shows, “Linnaeus grouped Tyson's chimpanzee with people, rather than including it in the crowded genus Simia with all the monkeys and all other apes" ("Border Troubles" 484). In addition, 1758's Systema

Naturae edition

describes Homo troglodytes as a species of "golden-eyed nocturnal cave dwellers" (Schiebinger 80). Given

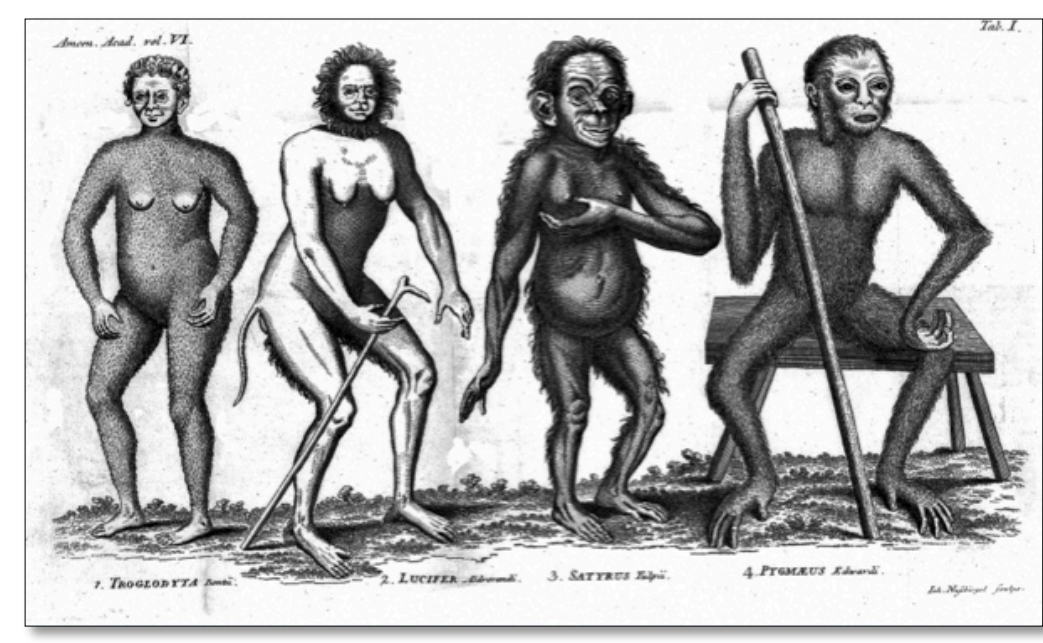

FIG. 2. From Linnaeus's Anthropomorphia. 1. Troglodyta bontii 2. Lucifer aldrovandi 3. Satyrus tulipii 4. Pygmaeus edwardi. 1760. Wellcome Library.

the myriad conflicting accounts and tales coming in from travelers and naturalists across the globe, one can understand a degree of confusion about what might actually exist. ${ }^{2}$ Even as Julia Douthwaite explains that classification and naming were of primary importance to naturalists at this time (17), one cannot forget the implications involved with linking a "creature" with a perceived lower rank to such a close relationship with the "thinking" men, Homo sapiens.

In Anthropomorphia (Fig. 2), Christian Emmanuel Hoppius's contribution to Linnaeus's "Academic Delights," the naturalist describes the existence of several

\footnotetext{
2 This species was identified because several of Linnaeus's countrymen reported them; Linnaeus even persuaded the Queen of Sweden to finance a search for a specimen by the Swedish East India Company (Schiebinger 80-81).
} 
intermediate forms between humans and apes. The second specimen, Lucifer aldrovandi, reproduces an image from a 1485 text, Travels in the Holy Land, which was in turn copied by Konrad Gesner and later, in 1645, the Italian naturalist Ulisse Aldrovandi, of whom we can assume Linnaeus recognized in its nomenclature (Meijer 35). This figure is particularly interesting because of the presence of a tail and female breasts - while we can only assume that Travels in the Holy Land depicts some type of baboon, the name suggests that this animal was considered by Linnaeus to be some type of "demon" from the mysterious, perhaps mythical place (the original image from the 1485 text includes unicorns and clawed salamanders). This also suggests the anxiety of miscegenation, where an ape or monkey-human union leads to a devilish, unnatural offspring. However, according to his own criteria favoring appearances, Linnaeus could not deny these intermediate beings a place in the hierarchical orders, but he did consider reason and speech a mark of "higher," Western humans, Homo sapiens (Burke 268). Overall, Linnaeus prioritized anatomical features as markers of the genus Homo, but, as Meijer quotes, he fretted over being unable to present a barrier between the apes and humans: "'It is remarkable that the stupidest ape differs so little from the wisest man, that the surveyor of nature has yet to be found who can draw the line between them"' (qtd. in Meijer 46).

Unlike Linnaeus's primary focus on outward appearances, when Buffon comments on the ape's affinities and analogies to human beings, he considers both the mind and body. One of Buffon's largest criticisms of Linnaeus's classifications lies in how Linnaeus, using appearance only, includes humans and apes together. As Douthwaite explains, Buffon's classifications did consider appearances and behavior, but 
he also believed that humans held a hierarchical place above animals with their intelligence and reason (17). Buffon's text proves particularly revealing in his definition of the human/non-human difference. In L'Histoire Naturelle, Buffon describes the species as having "the greatest resemblance to man; and, consequently, deserve[s] particular attention" (78). Although he did not believe that the human-like expressions revealed a soul (Liebman 669), in his own eyewitness account of "Le Jocko," Buffon's name for the chimpanzee, he describes a gentle animal and ascribes human-like emotions: "His air was melancholy, his gait grave, his movements measured, his dispositions gentle, and very different from those of other apes" (86-87). Because the ape's facial features and physical characteristics (Fig. 3) resemble humans "in a state of nature," Buffon understands how less educated and yet still "civilized Indians" chose to "associate him with the human species, under the denomination of Orang-outang, or wild man" (41). Buffon's text grapples with the idea of an animal soul, especially in regard to human assertions that apes, and the chimpanzee in particular, mimic human movement in a type of communication between species. Buffon borrows Cartesian language to decidedly convey his opinion that "Le Jocko" does not contain the same soul or intelligence as a civilized man:

Two bodies which receive the same impulse, two similar pendulums or machines, will move in the same manner. But these bodies or machines can never be said to imitate each other in their motions. The ape and the human body are two machines similarly constructed, and necessarily move nearly in the same manner. But parity is not imitation. The one depends on matter, and the other on mind. Imitation presupposes the design of imitating. The ape is incapable of forming this design, which requires a train of thinking. (73)

Buffon was not of the opinion that apes and humans should be classified together; although ape and human bodies are machines, he states that he "accorded them [apes] 
everything, with the exception of thought and reflection" (qtd. in Roger 244). While he feels that man "must put himself in the class of the animals that he resembles physically," he remarks that "man is a reasonable being, and animals are creatures without reason" (qtd. in Roger 240). Buffon's vacillation exemplifies the trouble naturalists had with considering humans as animals while also adhering to religious tracts that explicitly positioned humans above all other creatures.

Linnaeus and Buffon draw equivalencies between apes and humans - but with an unease and uncertainty about linking the two together as similar in kind. Even though

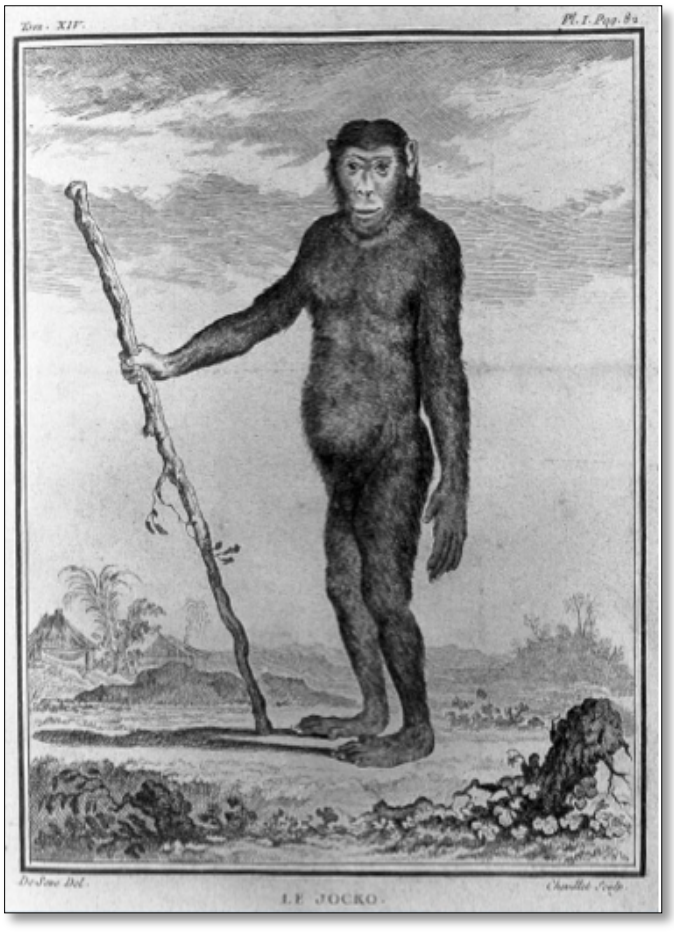

FIG. 3. Buffon's "Le Jocko," from the Histoire Naturelle. Engraving by Jacques de Sève, 1749. Wellcome Library. naturalists commented on and depicted intelligent apes, they still deemed them as strictly instinctual, without the rational mind to draw them toward Descartes's stipulation for human designation. Surprisingly, apes within the genus Homo were oftentimes considered similar and level with the "lower" and more "primitive" humans of Africa and Asia. In fact, reports of these supposedly lesser humans drew many similar images and descriptions that classify natives as animalistic, instinctual, and ape-like humans.

However, as Douthwaite posits, many of these comparisons invited concerns about how an animalistic, machine-like human could disrupt the divine order (18). Misinformation and second-hand stories prevailed, and with only subjective testimony as their guide, 
naturalists began to connect the Great Chain of Being by way of "lower" humans, either through myths of "wild men" or images and accounts of apes mating with human females. In both Linnaeus and Buffon's definitions of what is "human" and what is "ape," we are presented with not only names, or language, but are also privy to visual depictions of the naturalists' conceptual framework. Naturalists controlled the designation of what qualified as human through these images, drawing equivalencies between apes and "lower" humans, forwarding ideas of subtle gradations and distinctions between what might link these two families together. As Foucault explains, naturalists found a way to focus the new way of knowing through what people read and saw, creating the narrative of origins and classification: "visual representations will now at last be able to provide natural history with what constitutes its proper object, with precisely what it will convey in the well-made language it intends to construct" (Order 134). So, although not all naturalists were in agreement with the features and characteristics that should dictate one's place in the animal kingdom, these images convey Foucault's assertion that naturalists "employ the same grid; their gaze occupies the same surface of contact upon things" (Foucault, Order 135). When widely accepted, Linnaeus's system of nomenclature stipulated where an animal (including humans) belonged, and images solidified and reinforced this narrative. Humans that did not appear to be the same as Europeans were immediately suspect as different in kind - and this difference needed explanation. "Thinking," and the capacity to use reason, became a major prerequisite for admittance into the category of Homo sapiens. 


\section{The Human Difference \& The Language of Civilization}

"we are called to Sir W. Batten's to see the strange creature that Captain Holmes hath brought with him from Guiny; it is a great baboon, but so much like a man in most things, that though they say there is a species of them, yet I cannot believe but that it is a monster got of a man and she-baboon. I do believe that it already understands much English, and I am of the mind it might be taught to speak or make signs."

- Samuel Pepys, 24 August 1661

\section{"I am of the mind it might be taught to speak or make signs"}

In the quote from Pepys's entry above, the question of capacity becomes germane, for recognizing that "it might be taught" necessarily implies that the human or non-human must be intellectually available for education. Europeans still could not accept that native and "lower" humans were as developed as their own Enlightened and civilized selves, and as classification interests extended from apes to humans, the concern of breeding and lineage permeated conversations of defining "human" in terms of lower and higher orders. In order to define the "discovered" native populations as human rather than ape, naturalists had to consider features other than physical resemblance. Although they largely agreed that apes and humans, especially native human populations, which to the eighteenth-century European eye looked so different than them, were physiologically similar, some scientists relied on parentage and "blood" to determine their humanity. Because naturalists could not count on actual "specimens" from these newly discovered populations, they had to rely on ranking and classification methods they themselves employed in their own society. "Breeding" and lineage became the standard by which naturalists determined the native peoples' status on the ape-human scale, and they considered the range of difference as a marker for a given groups' animality or humanity.

Naturalists readily applied principles of how humans breed and select for traits in other animals to speculate on how native populations developed and distinguished 
themselves from others. The idea of "difference" permeates this thinking, and as Ritvo suggests in The Platypus and the Mermaid, "[e]ighteenth-century naturalists had concurred in dividing people into roughly geographical subgroups, although the number of subgroups, their precise territorial boundaries, and their distinguishing characteristics varied from authority to authority" (121). Each group's geography and perceived levels of development determined how different they were from other humans and defined their taxonomical rank (121). One can guess how Europeans ranked themselves on this scale; according to Europeans, the most developed humans were, naturally, Europeans. And while many of these determinations were based on appearance, such as Blumenbach

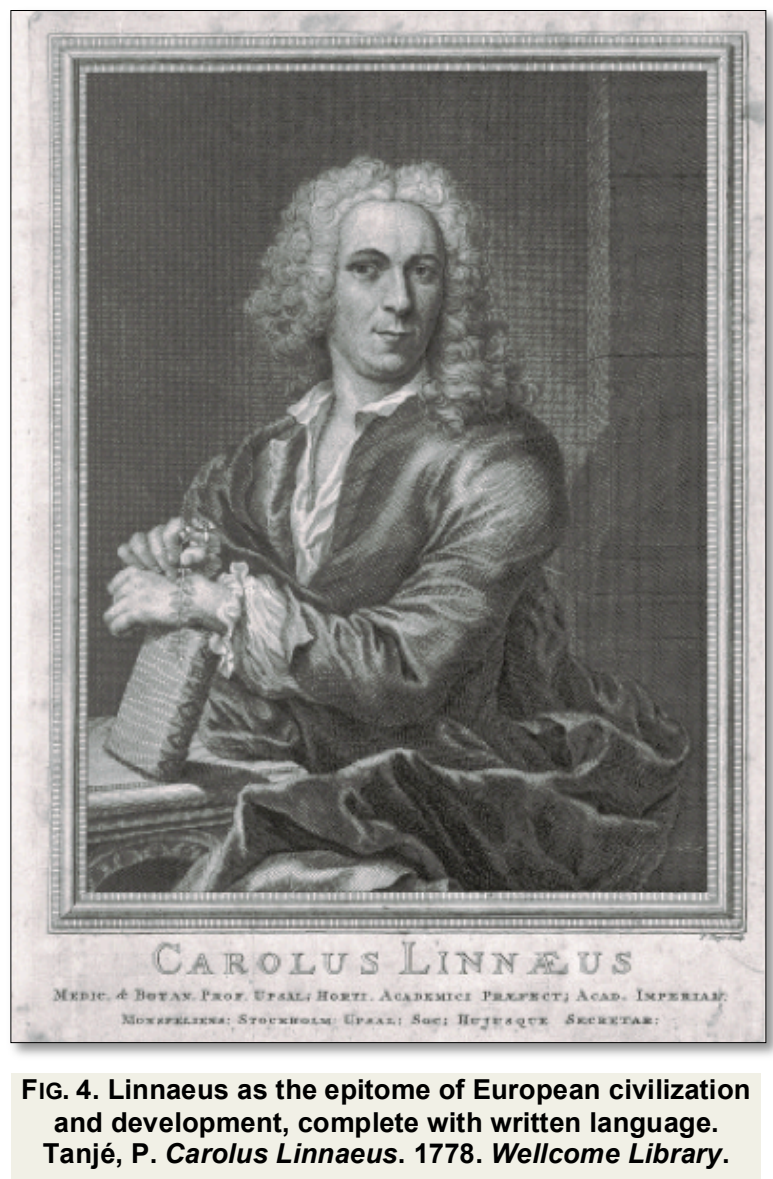

determining that Caucasians were the most "beautiful" (Schiebinger 129), others divided racial groups by their "degree of civilization - Caucasians, in one account, having 'an unbroken series of history"” (Ritvo, Platypus 122). Traceable lineage and language became tantamount to developmental status, and reinforced not only images of Europeans as more civilized than non-European peoples, but also notions of class hierarchies and nobility. 
In addition to or instead of analyzing a being's "breeding," some naturalists returned to the question of rationality or intelligence when they determined an animal human or non-human. When Lord Monboddo, who wrote several volumes on the development of speech and language, put forth his Antient Metaphysics, he suggested that humans evolved and became more civilized by socialization. In Metaphysics's third volume, he forwards his theory of "social evolution" and he traces how humans are closely related to apes: "the most primitive hominoids were Brutes and Tailed Men. Next came the Orang Outangs and Speechless Savages, and among these early 'civilization' or ‘social life' began” (Barnard 100). Others were less optimistic about perfectibility and considered language as a skill that those classified as "less" human might never achieve. As Patrick Brantlinger recounts, “[David] Hume's belief that 'there never was a civilized nation of any other complexion than white' and that 'negroes' have no 'ingenuity"' presented a particular combination of racism and pessimism to their educational capacities (4). Monboddo attributes the savages' speechlessness to more theological reasons, rather than an entire lack of the capacity to speak. He asserts that the fallen Adam and Eve marked the perfect being's downfall, but language and the arts redeemed humanity, enabling them to move from savage and primitive to civilized (Cloyd 170). $\mathrm{He}$ believed that certain groups of humans in Africa and Asia remained speechless, but that when those peoples are taught or form societal bonds, language and civilization follow. In a study of two "feral" children, Peter of Hanover and Marie-Angélique Leblanc, Monboddo combined their abilities and those of an orangutan, and determined that they fit into a series of stages of "universal human progress" (Douthwaite 24). This progression was ordered as follows: the "infantine stage," represented by Peter of 
Hanover, sees a non-bipedal human unable to speak until fifteen, the bipedal orangutan, modest and social, stands in the second stage, and Marie-Angélique's ability to acquire language and tool use places her in the third stage of development (Douthwaite 24). Perhaps surprisingly, Monboddo has classified the orangutan as not only human, but also in a higher state of progress than the feral child.

Alan Barnard forwards the claim that Monboddo's "notion that society predates language depends on his assumption that Orang Outangs belong to the same species as humanity in general" (98). If savages were humans, then the Orang Outang was as well the "savages" were in a marginally higher stage of social development, on their way to language acquisition (Meijer 60). In order for the primitive races to progress to more perfect states, they must learn to use language, but use it artistically, with sensitivity and critical thinking, more like Aristotle's "man," one "capable of comparing his sensations, mortal, capable of receiving intellect, and also of science" (Cloyd 161). Peter of Hanover did not learn to speak until he was fifteen, which most likely affected his "human" status until he could show himself as human in both mind and body. Not only did Europeans feel a call to define and rank how close animals are to perfection, they also needed to instill the will to perfection in their human relatives. Monboddo believed that religious and philosophical practice would be a necessary catalyst for improving natives or savages (Cloyd 170). Because white European men were the most civilized, they were, of course, the most qualified to civilize their primitive brothers.

Naturalists defined apes as animals that possessed hints of humanity, and while primitive humans existed on the line between animal and human, they differed from apes by their perceived intellectual motivations and seeming willingness and desire to become 
"better." Apes were captured and brought back to Europe, while African and island native peoples were oftentimes depicted as all too willing to join explorers on trips returning home. Their manners and to what "extent they were civil and civilizable" were important markers of development (Schiebinger 85). But this also opens up the conversation of how open humans really were to accept power and domination in their lives - those that were willing to be "improved" also helped to elevate their perceived developmental rank. This notion of the will to improvement guided naturalists and philosophers to the belief that native peoples aspired to be like Europeans, both in behavior and language. Of course, this only confirmed Europeans' beliefs that their cultures were the highest, and perfectibility became an indicator of rank: "Whether the writer speculated on the history of an entire people or compared different forms of society around the globe, it was widely believed that the English and French cultures of the time - thanks to their cultivation of the arts, sciences, and diverse forms of industry had achieved the apogee of cultural perfection" (Douthwaite 24). Ritvo makes reference to James Hunt's comments in 1863 , where he states, “the Negro race can only be humanised and civilised by Europeans" (qtd. in Platypus 125). In order for these primitive races to become fully human, they must accept the power of Europeans to educate, mold, and develop them, and also subscribe to the ideology of progress toward a more civilized existence toward "human." Any resistance to this narrative of progress and path to civilized personhood was construed as a look in the other direction, and explains a tendency to credit rumors of human-ape miscegenation. 


\section{The Woman And The APE - Crossing the Insuperable Barrier}

\section{"it is a monster got of a man and she-baboon"}

Although often left unmentioned today, many highly reputable eighteenth and nineteenth-century naturalists considered miscegenation not only a non-human problem, but also a question of human and non-human interspecies reproduction. As we have seen, naturalists noted and speculated on the resemblance apes share with humans, and as they did not have the language and scientific knowledge about descent and evolution at the time, they attributed this resemblance to what they understood about animal reproduction and breeding and applied it to humans and apes. Medieval texts forwarded the claim that the ape was a "monstrous offspring of humankind," and was a product of Adam and Eve's fall (Schiebinger 95). Notwithstanding the theological issues surrounding divine favor, naturalists attempted to explain the purported resemblance of apes and humans to the "primitive" human, and women, already considered lower and in a weakened state, were particularly dangerous temptations for these lascivious apes. These claims were not limited to speculative or more brazen naturalists; Edward Tyson is said to have remarked that apes "preferred blondes" and "Buffon and countless others told stories of East Indian and African women being suddenly attacked and ravished by these shameless animals" (Schiebinger 95). In the next century, Charles White repeated stories of apes absconding with "negro boys, girls and even women...as objects of brutal passion," and traveller's accounts of "lascivious males apes attack[ing] women" who "perish miserably in the brutal embraces of their ravishers" were summarized by Blumenbach and reprinted by the Anthropological Society (Ritvo, Platypus 92). In these accounts, we see suggestions of violence ("shameless," "brutal," "attack,") from male apes, but this ostensibly involves a 
blameless and victimized human female. Were women purely victimized, unwilling partners in a scandalous union, or were they sometimes acting of their own accord, choosing to participate in interspecies relations? With an already tenuous and crumbling barrier between divinely blessed and soulful humans to mechanistic apes, intimations of reproduction between the two call into question the human claim to superiority, and suggest the troubling claim that the soul and human nature might be a constructed barrier and not natural at all.

The suggestion of violence from male apes leads to an interesting question of agency and the role that women, albeit "primitive" women, played in the reproduction of hybrid and missing link-like creatures. The violent language used in the descriptions of human female / male ape relations implied that the male apes were oftentimes the aggressors, forcing women into unholy and unnatural unions. When Lord Monboddo suggested that male orangutans mated with human females, he determined that the resulting offspring were fertile ape-human hybrids (Barnard 99). As Schiebinger presents, the violence and hypersexuality of male apes was considered a factor in the ape-human hybrid: "Their venery was supposedly so great that male apes were thought to ravish human females in addition to their own kind" (95). In many of the accounts referenced above, the male ape was the predator, and the female human's rape and consequent conception was a result of the male ape's natural inclination to violence. However, the primitive woman was also something of a strange, unknown creature herself, and naturalists sometimes attributed the woman's own agency as setting these strange relations in motion, as Blumenbach did when he implied that some unions were voluntary, and, in fact, initiated by primitive women (Schiebinger 98). Schiebinger's research shows 
that naturalists considered apes and primitive humans results of mixed unions, with both as transitional forms between monkeys and humans (98) - African and Asian women were either forced or voluntary agents in this reproduction, and their offspring spread the more primitive traits into native populations. Human females were intermediaries, the tools for males to use to their own reproductive ends and explain the similarities and differences between male ape and human natures.

When considering Linnaeus's "The Orang-Outang carrying off a Negro Girl" (Fig.5), we immediately see the male ape in the tree with a swooning African woman slung across his hip. The African male attempts to reclaim her, but we can't be certain if he is aiming at the ape or the nowspoiled woman. The males are the violent actors in the image, with the females either fainting or quietly observing in the foreground. Females of any species were seen in this role - this trope of the passive female persisted and was repeated throughout writing and images of both primitive humans and apes in the eighteenth century, and, interestingly,

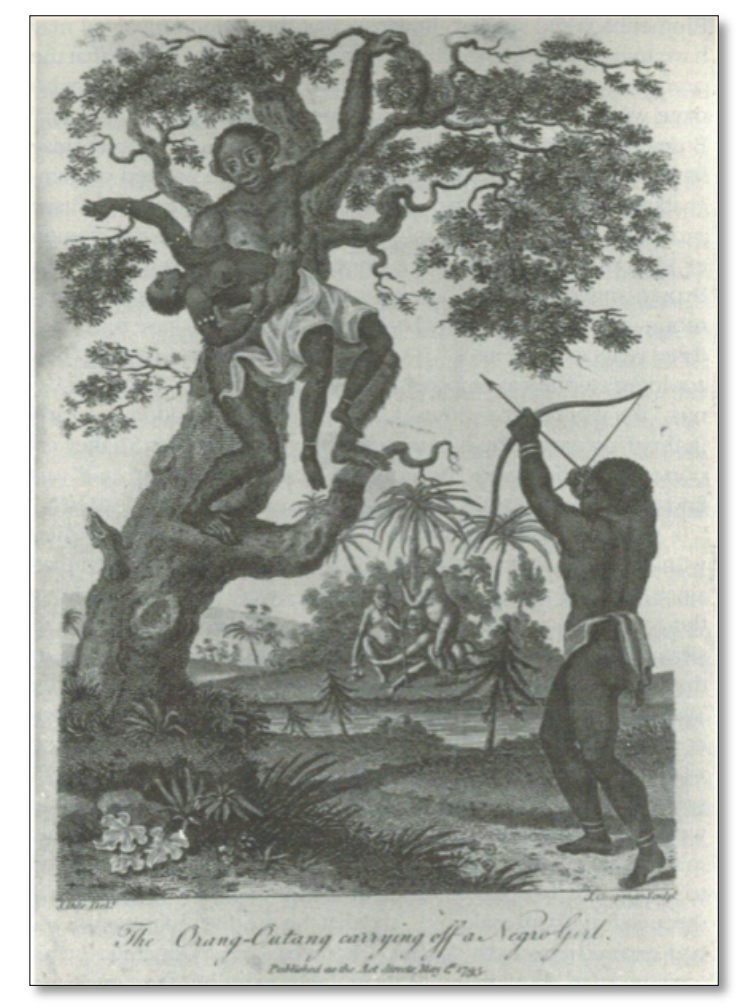

FIG. 5. "The Orang-Outang carrying off a Negro Girl," in Carl Linnaeus's $A$ Genuine and Universal System of Natural History. From Schiebinger's Nature's Body: Gender in the Making of Modern Science. Notice the almost indistinguishable difference between the male ape and human, and the ape-human hybrid offspring in the foreground.

although the male ape was customarily depicted as violent, lascivious, and brutal, the female ape was considered modest, gentle, and maternal (Schiebinger 99). So, while male 
apes were still viewed as violent, animalistic creatures, the female ape became an exemplar for women, behaving as the naturalists would like to see their own wives and daughters behave (Schiebinger 78). Gentility became the mode of social interaction for the middle class, providing ways to behave and mark themselves as "different" than the lower classes, and, by extension, the lower, less-developed "primitive" humans. Women were the conduits through which either animal or human qualities manifested themselves. The prospect of unnatural, and in a way, artificial, creatures introduced the idea of a being that could not be classified, named, or defined within the natural order. Its nature would span the line between animal and human, and therefore weaken the claim of a different or special human nature. Any "mixing" with the ape-like, uncivilized masses would deteriorate and weaken the already crumbling division between humans and animals, and unleash a potential usurpation of the highest order of humankind. The civilized woman must seek to distinguish herself from her lower human counterparts by rearing educated, literate, and well-behaved offspring, and maintain the natural order, in keeping with Chain of Being.

\section{Power, Progress, and Classifying Discourse}

In Discipline and Punish, Foucault claims that power is something that is exercised rather than a quality acquired or possessed. In the long eighteenth century, European males exercised their power by asserting themselves as the epitome of civilized development and conferred power only to those who wrote the narrative and defined the species. Within the development of disciplines and divisions of labor, Foucault claims that these establish their own hierarchies, and disciplines use "procedures of partitioning 
and verticality, that they introduce, between the different elements at the same level, as solid separations as possible, that they define compact hierarchical networks" (564). This verticality can easily translate to the ideas naturalists developed regarding the divisions and definitions of levels of humanity among apes and native peoples, and a European/non-European binary gave scientists ways to distinguish themselves as somehow higher than Others. These distinctions led to even further gradations between animals and between humans, invoking a scale of development: "The binary opposition between humans and animals has been historically parallel to a series of other oppositions, confined within the human species" (Ritvo, "Border Troubles" 497). In the case of human and non-human classification, naturalists enacted and exercised Foucault's "power-knowledge relations" in terms of how those with the power of narrative controlled the imagery and messages transmitted regarding the voiceless populations. But with their power of description came responsibility, and with an increased visibility and status of natives as "less" than European men, many naturalists and intellectuals took it upon themselves to assert the goal of progress and civilization as a guiding mission, often using this as a reason to justify colonization and dominance. Finding where everything "fit" in the Chain of Being allowed Enlightenment naturalists to establish criteria necessary to move forward in civilizing and Christianizing missions around the world. In the seventeenth and eighteenth centuries, French, Dutch, British, and Swedish overseas colonies and empires proliferated; naturalists, missionaries, and government officials often used scientific treatises as justifications for their treatment of native peoples. Douthwaite explains, "the general tendency was to assume that European society represented a paragon of intellectual and social progress that other peoples would 
do well to emulate" (1-2). When missionaries and explorers visited strange and wondrous places, they occasionally convinced (or, as the story often went, were convinced by) natives to return back to Europe with them. However, rather than showing that native peoples were able to be civilized on their own accord, it could be argued that this gave Europeans the opportunity to depict themselves as a necessary catalyst for this supposed need to be realized: "although savages and barbarians may eventually leave their 'rude' condition and join the 'respectable' nations of Europe...they have not progressed on their own and may very well need the assistance of Europeans to achieve civilization"

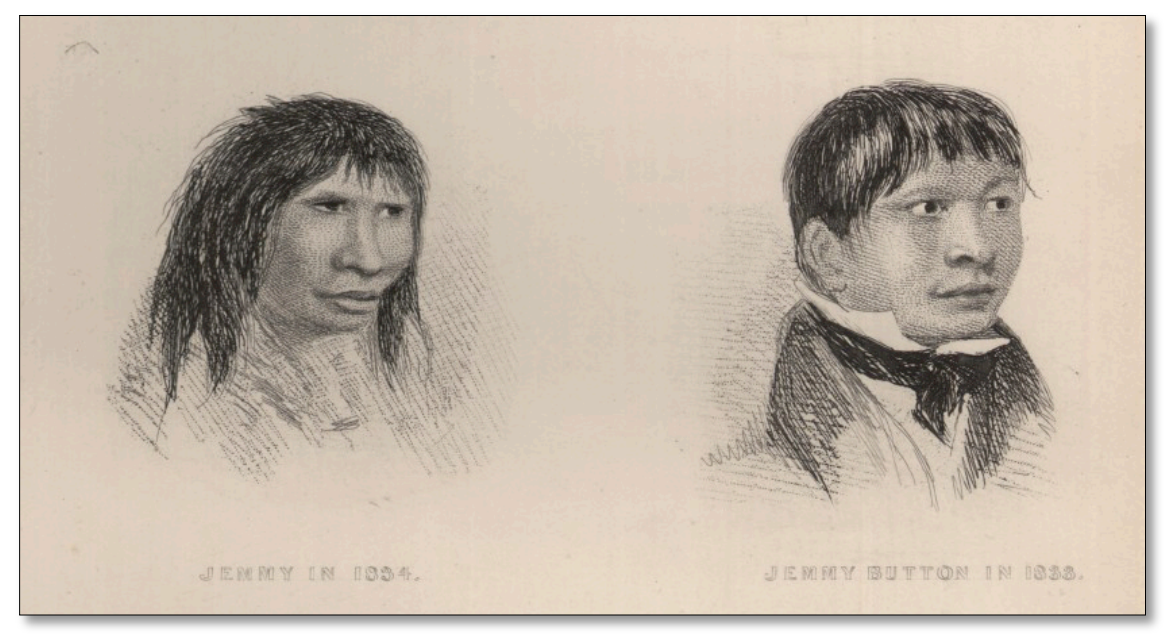

FIG. 6. Jemmy Button, a Fuegian "adopted" by Robert Fitzroy during the Beagle's voyage, before and after his trip to England. The Complete Works of Darwin Online.
(Brantlinger 5).

Even Charles

Darwin, during

his journey as the

Beagle's

naturalist,

compared and

classified native

human societies along a scale of "more" or "less" like Europeans, and made observations about the perfectibility of "primitive" humans: "I believe, in this extreme part of South America, man exists in a lower state of improvement than in any other part of the world" (204 [my emphasis]). With a civilizing "mission," the European explorers and settlers imposed a certain concept of power and progress on native peoples.

While the natives were considered "less" than human, or ape-human hybrids, these systems inherently disallowed the natives any "progress" into the civilized world; 
the native peoples were always forced into the subject position of the viewed rather than the viewer (McClintock 93). This gave Europeans free reign to slip their perceptions of "lower" peoples into their treatment of them, and using language gave them the power of description rather than the other way around. When taken together, the images and corresponding text present a compelling portrait of eighteenth-century beliefs and developing theories of descent, relations, and similarities between humans and apes. Foucault's archaeology of the power of the dominant classifying discourse and way of knowing presents the assertion that "only Man has the capacity to form ideas of 'species' and 'genus'... in other words, the ability not just to compare, but to compare within a hierarchy of knowledge" (Barnard 103 [my emphasis]).

\section{Ways of KnOWing the Creature and The Clone}

When Armstrong engages Foucault's argument in her own discussion of the rise of domesticity in "Some Call It Fiction: On the Politics of Domesticity," she points to the domestic sphere and the rise of the novel as a location of the gaze, and considers this as one of the primary locations of power-relations (572). If we extend the argument to the present discussion, placing women in direct contact and subjugation within the structure of domestic power-relations can help connect the rise in the focus on gentility and the household's visibility; these rose at the same time as the naturalists' power of imagery and classification, and, as Armstrong suggests, moved power into a more intellectual show of force rather than outright violence (579). In the image of a male ape violently carrying off a woman and forcing her into an unnatural situation of miscegenation, we can see the gendered power structure within the implication that males of any species are 
"higher" than women, and that this difference is "natural" within all societies. Anne McClintock, in "The Angel of Progress: Pitfalls of the Term 'Post-colonialism'," proposes considering power as a narrative, and the ideology of progress as a way to use power structures and justifications of colonialism can extend to European classifications, for when Enlightenment naturalists declare classifications with certain ordering systems, the European worldview becomes a critique on other peoples' lives and status as humans. Controlling the narrative gave European men power over the stories of the voiceless apes, women, and native peoples.

With the rise of the middle class in urban European cities, women and men's increasing literacy rates and leisure time demanded books. As Armstrong points out, women's novels were often seen as primers for women, modeling desired behavior for their female readers, and the qualities they should desire in potential husbands (574). One such example, Fanny Burney's Evelina, published in 1778, ends with an astounding scene related to the conversation about human-ape relations, similarities, and behavior. At the close of the novel, the brazen and outspoken Captain Mirvan brings a monkey dressed as a man to a dinner party, causing the entire party to erupt into chaos, violence, and frightened women. The scene raises numerous themes and issues within eighteenthcentury literature, but also continues to puzzle critics in their conversations of the novel. For my focus, this passage is noteworthy because it speaks to not only the perception of monkey and ape similarities to humans, but also the illustration and comparison of various reactions between the men in the scene. Mirvan and Mr. Lovel portray ungentlemanly behavior, either by bringing the monkey to the party (Mirvan), or becoming violent in the face of humiliation: "Poor Mr. Lovel, too much intimidated to 
stand his ground, yet too much enraged to submit, turned hastily round, and, forgetful of consequences, vented his passion by giving a furious blow to the monkey" (Burney 432). On the other hand, Lord Orville, Evelina's genteel and considerate suitor, presents himself as even-tempered, patient, and violent only when necessary to restore order. When he sees the violence inflicted on the creature by Mr. Lovel, he acts in a most gentlemanly manner, first protecting his love, and then acting "ever humane, generous, and benevolent, he quitted his charge, whom he saw was wholly out of danger, and seizing the monkey by the collar...with a sudden swing, flung him out of the room, and shut the door" (Burney 432). Evelina makes the right choice, and her union will reproduce the civil, gentle humans so desired, removing one more potential "savage" union and preserving societal order and purity.

Evelina considers the social position of its characters as a mark of civilization; their parentage becomes a marker of their place in society. As Susan C. Greenfield suggests, the eighteenth-century man or woman considered their "breeding" as an indicator of their "social refinement," positioning them on the "spectrum between vulgar and polite" (423). Politeness and behavior is held up as the highest of human virtues, and Patricia Hamilton explains that Evelina considers the conversation of the ape (animal) and human as an issue of gender and power wrapped up in the narrative of politeness and good behavior (417). Burney's novel offers an illustration of how cultural artifacts replicated the ideas naturalists presented. Greenfield notes that Lord Orville can be considered as 'the 'noblest of men,' 'superior to his race,' and 'of a better order of beings"” (427). Evelina forwarded the European view that good breeding, polite language, and genteel behavior were ways for human men to distinguish themselves as more 
civilized and developed than native Others, and that the modest lady would provide civilized children well-suited to continue the civilizing mission and message.

Evelina exemplifies, even in a short passage, how the dominant "way of knowing" proffered by Foucault pervades our cultural artifacts. In particular, when artists and writers look for ways to convey what it means to be "human" in their time, knowledge of the origins of how we classify and determine humanity are valuable indicators of the cultural subject position and lens through which we view humans and non-humans. When Armstrong indicates the power relations inherent in Western literature, we can also see how certain types of writing attempt to resist these ideologies of progress, control, and ways of knowing. Foucault's power relations and archaeology of discourse seem to suggest that the dominant classifying and naming discourse silences all other modes of "knowing." If there is one particular way of knowing, then the knowledge bases outside of this discourse must be Other, and less legitimate. As Donna Haraway notes, the idea of a discourse controlling knowledge and what can be known exerts a silencing power over other systems of knowing: "the power of naming a thing is the power of objectifying... The other is simultaneously produced and located outside the more real in the twin discourses of life and human sciences" ("In the Beginning" 480). We can look to literature to consider how authors respond to and interact with social constructions, or, as Annette Kolodny remarks, see "literature as a social institution, embedded not only within its own literary traditions, but also within the particular physical and mental artifacts of the society from which it comes" (4).

The power of naming the "human" can move from cultural and social changes in science to a larger focus or question of the "human" in separate terms of mind and body, 
and how literature can provide examples of ways authors have resisted the classifying discourse in an attempt to see "human" as an empathetic and inclusive distinction between all animals, rather than a specific species and civilization. In short, literature can provide clues in the pursuit for ideological codes marking how we have both participated in and moved away from the classifying impulse. These moves of resistance begin quite early after the classifying discourse began in the 1730s, a decade that witnessed a widening divide between scientific optimism in progress and mastery of the natural world and the public's understanding of increasingly inaccessible scientific language. The reading public became wary of potential moral lapses in scientific practice, and the specialized discourse in which they did not participate invoked images of scientists working in the shadows of an ethical and "just" society (Douthwaite 13). In the remaining two chapters, I will discuss how Frankenstein and Never Let Me Go represent waypoints for the "human" progression from body to mind, and resist the dominant discourse of naming and classifying to encourage other "ways of knowing." In Frankenstein, Victor's un-named and un-defined creature seems to represent both adherence and rebellion to definitions of the "human": his new species cannot be defined as "human" because of his appearance, as would coincide with taxonomists' points of view, yet his civilized education and language seem to point to what Monboddo would consider a telling mark of Homo sapiens. Shelley's work stands against a strictly Linnaean or classifying discourse's definition of "human" and considers other ways of knowing and thinking about human nature, including ideas of reproduction, progress, and the soul. 


\section{CHAPTER 2}

\section{THE BARRIERS BETWEEN: FRANKENSTEIN'S ENLIGHTENED NON-HUMAN}

In the preceding chapter, I argued that Foucault's archaeology of power relations can extend from the power of classifying and naming the "human" to an exegesis of texts, and those texts serve as viable examples of humanity's attempts to grapple with burgeoning ideas of the "human animal" while still retaining the distinction of the human mind, body, and soul. However, although writers and naturalists accepted and often endorsed the classifying discourse, some took exception to certain unverifiable arguments and wrote in ways that appear to offer resistances to this impulse of withholding "humanity" from those creatures and beings that seem thoughtful, soulful, and humane. In this chapter, I will offer an investigation of perhaps the most famous of creatures, the “Monster” from Mary Shelley’s 1818 Frankenstein.

While many may argue that Frankenstein has too often been the subject of inquiry when analyzing nature, and, more particularly, human nature, I would argue that although Shelley's text is routinely seen as a critique of scientific hubris and a warning about the dangers of silencing the female's role in reproduction, these critiques overlook the novel's attempt to counter many naturalists', and, consequently, the reading public's, assumptions of "humanity" and what makes for a good human being. As naturalists" texts became accepted as the epitome of researched and thorough inquiry into our world and 
the creatures within it, we must look at how these texts educated or trained readers to "see" what the dominant discourse found important and worth classifying as either the same or different. The social aspects of reading cannot be overlooked, for as Lord Monboddo argued, the connection to language and social interaction are the exact behaviors that mark us as human. When Annette Kolodny argues for the applicability of this idea toward often-analyzed texts, she notes that "we appropriate different meanings...at different times - even from the same text - according to our changed assumptions...for insofar as literature is itself a social institution, so, too, reading is a highly socialized - or learned - activity" (11). As previously mentioned, during the time of Frankenstein's publication, the social audience was changing. The rising middle and leisure classes set a high value on a woman educated in specific subjects; as argued by Patricia Fara, highly genteel and civilized women were members of a growing readership, and with that, a growing customer base: "By the end of the eighteenth century, knowledge of natural philosophy was a badge of genteel culture, promoted by campaigners such as Edgeworth and [Erasmus] Darwin, but also exploited commercially in the creation of a lucrative female market" (18). As the previous chapter has explained, this "knowledge of natural philosophy" included an education within the purview of the dominant, masculine "way of knowing."

\section{A Human Education - Getting to The Body Of KNOWLedge}

In Frankenstein, Mary Shelley explores the question of the "human" and continues to question and test the philosophical mind-body problem of a creature whose taxonomy is uncertain and who eludes classification. However, before questioning the 
creature's place in the Chain of Being, we must establish Shelley's place within what I have termed the dominant, patriarchal classifying discourse. As the daughter of the philosopher, writer, and publisher William Godwin, Mary Shelley can be shown to have been familiar with the works of major naturalists, including Linnaeus and Buffon ${ }^{3}$. Additionally, these volumes played no small part in ushering in a new, less religious scientific community and, perhaps to the chagrin of a rather religious Linnaeus, more secular societal concerns (Knellwolf and Goodall 10). As Knellwolf and Goodall note, the move away from divinely inspired human exceptionalism brought new complications to deliberations on mankind's purpose, especially when "considered in light of...Buffon's accounts of the resemblances between the human physical frame and that of apes" (10). Shelley's creature merges these two apparently mutually exclusive sides - the animalistic "ape-like" creature with the seemingly divinely ordained and civilized soul.

Judith Barbour's study on Mary Shelley's juvenile readings reveals just how close to this dominant discourse the young woman may have been. In her article, "The Professor and the Orang-Outang: Mary Shelley as a Child Reader," Barbour forwards the assertion that Frankenstein owes itself to Shelley's early reading experiences and studies (33). Barbour locates a chapter from Godwin's adaptation of Oliver Goldsmith's 1774 History of the Earth and Animated Nature entitled "The Orang-Outang; or Wild Man of the Woods," which "introduces young readers to the scientific investigation of primates the Linnaean order embracing man and ape - but intermingles anecdotal stories about the as yet unidentified African gorilla with empiricist studies" (33). If Shelley was familiar with these accounts, we can see how her creature may have been a reflection of this

\footnotetext{
${ }^{3}$ William Godwin wrote articles for the Juvenile Library under a pseudonym, including "The OrangOutang; or Wild Man of the Woods." The Juvenile Encyclopedia described Linnaean taxonomy, and lifted images of apes from Buffon's L'Histoire Naturelle (Barbour 40-41).
} 
newly discovered intermediary between the rational human mind and the terrestrial body of instinct and passion. The creature occupies the middle ground, and is "equally ambiguous: is he an orphaned soul, rejected and cursed for crimes he never intended to commit, or is he a 'cruel and lascivious ape' like Goldsmith's orang-outang?" (Barbour $33)$.

When we consider the growing education and literacy rates among women at this time, we can trace the pervasiveness of this cultural shift towards a classifying discourse. Patricia Fara's study on Shelley's education is particularly applicable, for if Shelley's readings did include ideas from Buffon and other naturalists, the debate or conversation regarding the human "animal," their bodily relations to lower creatures, and the possibility of other soul-bearing animals becomes a viable avenue for analysis. As Fara notes, "the central core of Frankenstein, the creature's account of his initiation into human society, enables Shelley to critique European culture and morals" (26). Yet, in many ways, like Buffon and others, Shelley also focuses on the human "difference" in regards to the creature's physical form, and rather than studying the creature's body in reference to what $i s$, she often draws on the fear and shock of people's encounters with something or someone who is not like them. Mary Favret simplifies this notion by saying "Shelley's novel moves beyond the notion of bodily effects into the realm of bodily differences" (57). So, while Frankenstein explores the question of the human mind-body problem, a substantial part of the terror the creature wreaks places a vast store in the physical body and appearance, marking it as different, as was often the focus of naturalists' descriptions and images of humans and animals. 
Readers sense the creature's vacillation between intellectual and animalistic tendencies, and Shelley's unease in this strict definition is notable. When Foucault describes this unease, he frames it within the power of the classifying discourse and nomenclature, as a way to mold and characterize a being before knowing it: "Before this language of language, it is the thing itself that appears, in its own characters, but within the reality that has been patterned from the very outset by the name" (Order 130). At the beginning of the scientific boom of the 1700s, much of the "science" being practiced was fully accessible to educated readers - in fact, it "embraced all kinds of amateur contributions" (Douthwaite 5). This included, among others, travellers' eyewitness accounts, reports, and personal accounts of experiments. Yet, as Linnaean nomenclature and information gathering became more and more systematized, scientists' reading audiences' observations were increasingly marginalized and discredited. As this shift occurred, readers' optimism and confidence in science waned; specialized disciplines and boundaries between scientific genres barred the audience from the now more private experiments and results (Douthwaite 5). In this way, we can see a shift from the prevailing optimism of science as the great progressive force to a potentially powerful and dangerous force against humankind's best interests. As Douthwaite puts it, "the representation of human experiments in literature became increasingly fraught with anxieties about the regulatory public eye and the dangers of meddling with nature" (10).

Victor Frankenstein's creature is never named, never classified with a place in society, or even within the purview of living beings. By being denied a place within the natural order, he therefore cannot be "known" within the taxonomic system established by naturalists. Nevertheless, although seen as the Other and non-human monster, Shelley 
presents a being which shares many human traits and behaviors, "including consciousness, language, emotion, and hominid form" (Engelstein 183). The creature is created in the image of man and Frankenstein expects the image to regulate the remaining traits. Frankenstein is working under the assumption of many naturalists and scientists before him; he holds appearance and physical make-up to be the determinant of the being's status.

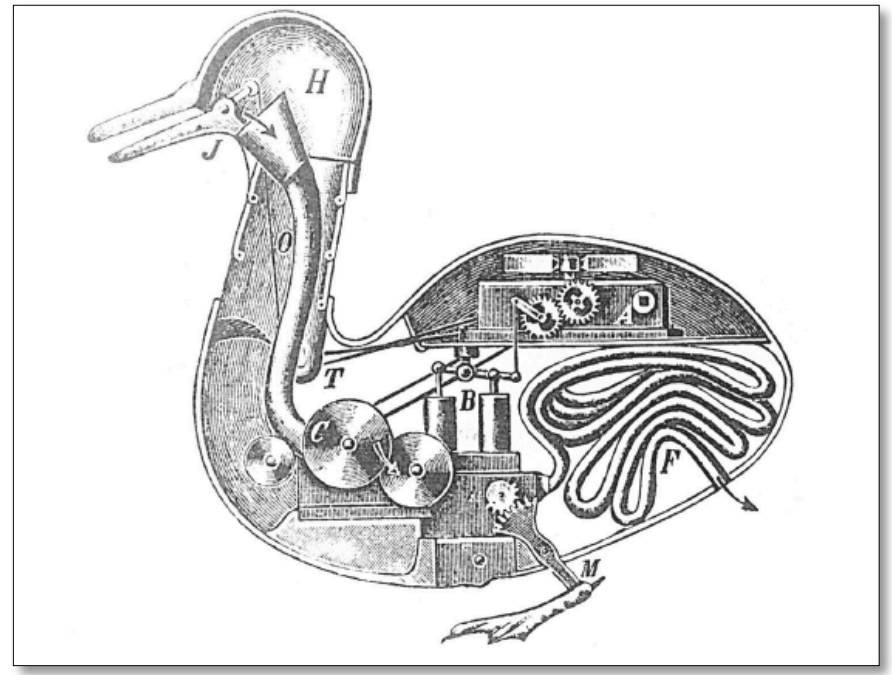

FIG. 7. The Defecating Duck, one of Jacques Vaucanson's automata. From Jessica Riskin's "The Defecating Duck, or, the Ambiguous Origins of Artificial Life."

However, as Douthwaite asserts,

when Victor animates the creature, it instead represents a "profound alteration in humanprimate morphology...the creature's gigantic body is scarred by science and embodies a sinister kind of artificiality that challenges his human status" (211). Frankenstein's creature represents a disconnect between the construction and physical constitution of a human and the power of the human gaze to "see" those constructions as human. As Judith Halberstam famously notes, "The production of the monster by Frankenstein throws humanness into relief because it emphasizes the constructedness of all identity. While superficially this novel seems to be about the making of a monster, it is really about the making of a human" (38). Just as Vaucanson's duck (Fig. 7) was a supposed construction of the internal functions of an animal, it was not seen as a true "duck." Yet, as Halberstam guides us, the constructedness calls attention to the seemingly mechanical 
workings of a "real" duck's physiological processes and calls attention to the criteria we hold as the determinants of difference.

\section{The Creature's Body and THE Viewer's Gaze}

We cannot dispute that Victor Frankenstein makes many mistakes in the course of the novel, and we cannot be surprised that when Frankenstein first sees his animated creation, he finds him a hideous monster. Victor's way of knowing within the dominant discourse provides that he will classify and compartmentalize living beings, what Foucault touts as a discourse prioritizing the physical body. When Frankenstein arrives in Ingolstadt, he forms opinions on his professors' natures and intelligence based on their appearance. For example, when describing M. Krempe, we can see Victor's immediate assessment: "I did not feel much inclined to study the books which I procured at his recommendation. M. Krempe was a squat man, with a gruff voice and repulsive countenance: the teacher, therefore, did not prepossess me in favour of his doctrine" (28). Yet his opinion of M. Waldman is different, and his appearance apparently helps his case, for Frankenstein describes him as "very unlike his colleague. He appeared about fifty years of age, but with an aspect expressive of the greatest benevolence... His person was short, but remarkably erect; and his voice the sweetest I had ever heard" (28). When compared with Buffon's description of Le Jocko, we can see the similarities in discourse:

"The orang-outang which I saw, walked always on two feet, even when carrying things of considerable weight. His air was melancholy, his gait grave, his movements measured, his disposition gentle, and very different from those of other apes" (86-7). So, when 
Victor finally sees his creation as a living being, perhaps we are not so surprised that he forms an immediate judgment of its character and personality.

Clearly, when Victor begins his work, he does not expect a monster. He begins with a fascination for the human body and its beauty in movement, and searches for a way to control the knowledge for himself: "One of the phenomena which had peculiarly attracted my attention was the structure of the human frame, and, indeed, any animal endued with life. Whence, I often asked myself, did the principle of life proceed?" (31). He assumes that the parts collected for the project will add up to a unified whole, and therefore composes a body of parts from beings already incomplete, from the "dissecting room and the slaughter-house" which housed bodies parted from their unique souls (34). And, at first, Victor does not see himself as creating a human from these broken materials, but his zeal gets the better of him. This is the point where many note Frankenstein's movement from scientific inquiry to dangerous delusions, when he moves from "doubt[ing] at first whether I should attempt the creation of a being like myself or one of simpler organization; but my imagination was too much exalted by my first success to permit me to doubt of my ability to give life to an animal as complex and wonderful as man...It was with these feelings that I began the creation of a human being" (32-33). Not shortly after Victor resolves to re-create the human, he thinks otherwise, because the construction and appearance would be necessarily different.

When Frankenstein realizes that the creation will not have the exact appearance of a civilized, Western European human being, he decides to make the creature even more perfect. During the creature's composition, Victor decides, "As the minuteness of the parts formed a great hindrance to my speed, I resolved, contract to my first intention, to 
make the being of a gigantic stature" (33). At this point we can see Victor usurping the divine Chain of Being, moving a new species into the hierarchy, and taking on the role of a blessed Creator: "A new species would bless me as its creator and source; many happy and excellent natures would owe their being to me. No father could claim the gratitude of his child so completely as I should deserve their's" (33). These delusions are quickly reversed, however, when Victor sees the creation come to life, and he realizes that his attempt to introduce a creature superior to humans disrupts the "natural" order. The creature's appearance, with his "yellow skin [which] scarcely covered the work of muscles and arteries beneath," long black hair, "watery eyes," and "shrivelled complexion," denies him humanity (35). Victor often describes his horror at the monster using the names he has available that properly reflect his fear and disgust: "I beheld the wretch - the miserable monster whom I had created" (36). The creature, when subjected to the gaze of a human observer, suddenly becomes a monster. While no longer a human being, it is also no longer a blessed new species. As Victor notes, "I had gazed on him while unfinished; he was ugly then, but when those muscles and joints were rendered capable of motion, it became a thing such as even Dante could not have conceived" (36 [my emphasis]).

Clearly, to the characters within Frankenstein, the creature is not human. This is established as soon as they see the creature, and is a fitting example for how the classifying gaze works into distinctions between "them" and "us." When it comes to appearances, the difference is what matters, for as Engelstein notes, the "great shock generated by viewing the Creature originates in this consistent similarity to the human form and expression, interrupted searingly by deviations from the expectations of 
humanity raised by the general conformity" (193). The creature does not look like a human, and must, therefore, not be. When the creature moves into the view of "society, people turn from him because of differences that are primarily aesthetic" (Douthwaite 212). The creature is most frightening because he does strike some sort of chord with humans - he acts like a human, and thinks like a human. So, while he gives the "impression of physical constraint," the "expression of its mental life through gesture" turns him into a frightening human-animal hybrid (Engelstein 196). Yet, as we return to Halberstam's reminder of the making of the human, we can see how the human defines the creature as a monster, and attempts to fit it into an ordered system of hierarchies. As Engelstein explains, the "Creature is not in itself a monster; it becomes monstrous by exposing the animality of the natural human, and never so clearly as when it displays its sophisticated mental life through the physical expression of passion in gesture and countenance" (196).

Shelley complicates the matter of naming, classifying, and ordering the creature by giving him a thriving and highly developed intellectual life. The creature demonstrates a certain disconnect between the ideas of the naturalists' gaze and their considerations of the mind and soul of a creature, and how these distinctions might preclude the initial outward appearances. When Peter Brooks considers the definition of the "monster" within Frankenstein, he echoes the shift, where "he [the creature] puts into question the meaning of looking, of optics, as the faculty and the science most commonly used to judge meanings in the phenomenal world" (370). The creature is only "evil" when he is seen, and the power of the gaze does not hold sway without image: "It is only when sight is allowed to influence hearing that the creature becomes a supernatural terror" 
(Douthwaite 219). When the creature interacts with humans who cannot see him, his language and learning present a mental image of humanity. But even if the creature

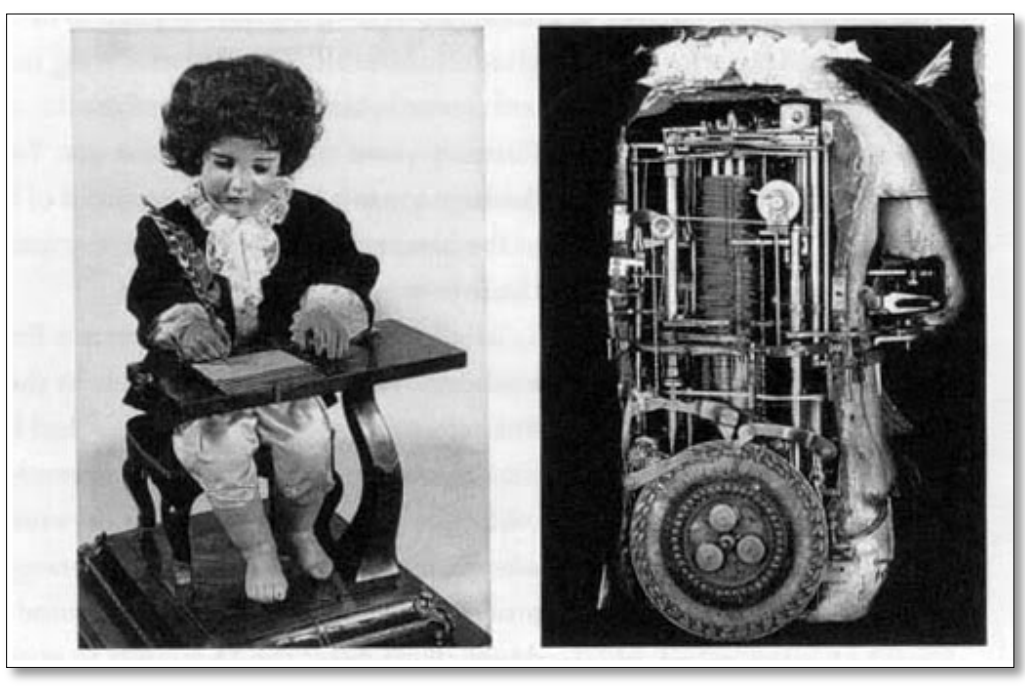

FIG. 8. One of Jaquet-Droz's automata, engaged in scholarly pursuits. From The Female Thermometer: Eighteenth-Century Culture and the Invention of the Uncanny. looked exactly like a

human, would he have

the intelligence and

"soul" to make him a

civilized and valued

human being? Consider

Jaquet-Droz's

automaton (Fig. 8);

although obviously not

human, the boy is engaged in scholarly pursuit. The boy copies human action, and the choice of constructing such a seemingly "educated" machine perhaps contributes to our fascination. Is Frankenstein's creation also a mechanistic imitation of the human, copying the movements and narrative as a man-made, unnatural creation?

\section{The Genteel And Social Monster}

Frankenstein's second volume opens with the creature's own personal narrative of education and discovery, and chronicles the time spent away from Victor immediately following his creation. The creature wanders the forests, initially caring for his immediate physical needs, but shortly thereafter, he seeks to discover who he is. When the creature finds himself in the presence of humans, specifically the De Lacey family, he observes human behavior and language, and vows to mold himself into their image, learning to 
adapt himself to their natures. The first step, then, is the creature's decision that their ways were the right ways, and that this is what he should be. As with explorers' narratives of indigenous peoples, the creature seems to demonstrate the will to civilize himself. In fact, this will should be a marker of the creature's human nature, as at this point in the novel, the creature's "instinct" is to become civilized. Just as Victor uses the naturalists' discourse of appearance to describe his subjects' inner qualities, the creature conveys that the De Laceys' appearances give off the impression of civilized humanity: "Nothing could exceed in beauty the contrast between these two excellent creatures. One was old, with silver hairs and a countenance beaming with benevolence and love: the younger was slight and graceful in his figure, and his features were moulded with the finest symmetry" (75). When he hears them talking to one another, he remarks that he wants to understand that power because as "a godlike science...I ardently desired to become acquainted with it" (77). Yet, at first, he must overcome his repugnance toward himself, perhaps in itself a sign of his burgeoning human nature. For, if he sees himself as monstrous, is he not exhibiting the same instincts and fears as humans? He realizes that his mastery of language may be the only way to counteract the frightening power of his image:

Although I eagerly longed to discover myself to the cottagers, I ought not to make the attempt until I had first become master of their language; which knowledge might enable me to make them overlook the deformity of my figure; for with this also the contrast perpetually presented to my eyes had made me acquainted...how was I terrified, when I viewed myself in a transparent pool! At first I started back, unable to believe that it was indeed I who was reflected in the mirror; and when I became fully convinced that I was in reality the monster that I am, I was filled with the bitterest sensations of despondence and mortification. (79) 
The creature uses his time observing the De Lacey family to learn about human emotion, passion, and civility. Even when he begins his narrative, the creature speaks in terms of his emotions and intellect: "II shall relate events that impressed me with feelings which, from what I was, have made me what I am"' (80). The creature's emotions have shaped his character, and he makes repeated references to his senses and passions. In fact, he often points to the ways in which he is peaceful and civilized, as is the case when he speaks of learning from Voleny's Ruins of Empire: “"but when I heard details of vice and bloodshed, my wonder ceased, and I turned away with disgust and loathing"' (83). Readings from Western culture influence his emotions and civilized nature, for, as he recalls his education, he notes that "I sympathized with, and partly understood them, but I was unformed in mind...I learned from Werter's imaginations despondency and gloom, but Plutarch taught me high thoughts" (89). These scenes of reading occur when Felix is teaching his love, Safie, the local language and history, which inform the creature's preference for Western Civilization as the height of human society. Just as Safie long ago learned to "temper" her soul according to a move away from her own native "followers of Mahomet," so too did the creature's soul grow "accustomed to grand ideas and noble emulation for virtue" (86). Yet not only does the creature learn from Felix and Safie's readings on history and virtue, but he also learns about the value of love and companionship.

As he has gleaned from the De Laceys' lessons, the creature learns to hold Western society up to the "highest" form of humanity, and he wants to participate. Just as Lord Monboddo and others stipulated that the social group is a necessary component of language and "human" status, the creature requests that Frankenstein create a second 
member of his species. In his attempt to convince Victor, the creature uses his newly acquired powers of linguistic persuasion, playing on human nature's passions and sympathies. He declares to Frankenstein, "Let your compassion be moved, and do not disdain me" (69) and declares Victor his regulator, making him responsible for not only his violence, but also his docility: "I am thy creature and I will be even mild and docile to my natural lord and king, if thou wilt also perform thy part, the which thou owest me" (68). Before murdering William, the creature declares that he was even so kind that he was, for a time, human, declaring that he was "benevolent; my soul glowed with love and humanity; but am I not alone, miserably alone?” (68 [my emphasis]). When Frankenstein is not quite convinced by these claims of humanity, the creature moves to cultivate Victor's compassion in his request for one "like" him.

Because Frankenstein will not accept the creature's pleas and claims to human nature, the creature changes tactics and begins to argue for the sake of his own species. The creature wants a female companion, a mate, and, as he assumes that she will be just as susceptible to the power of appearance, requests that she be ugly as well, for "one as deformed and horrible as myself would not deny herself to me. My companion must be of the same species" (101). When he abstains from using the argument of himself as a human, Victor begins to relent - and also refrains from calling the creature a human: "I felt that there was some justice in his argument. His tale, and the feelings he now expressed, proved him to be a creature of fine sensations" (102). Although he eventually consents to create the female companion, he still finds himself repulsed by the creature's appearance, and he expresses his own battle between the mind, with compassion and sympathy, and instinct, which makes him want to turn away, "sometimes [I] felt a wish to 
console him; but when I looked upon him, when I saw the filthy mass that moved and talked, my heart sickened, and my feelings were altered to those of horror and hatred" (103). The creature's persuasive language and appeals to emotion and sympathy arouse the notion of a commonality between himself and a "fellow-creature," but Victor cannot move away from his appearance. Why can Victor not get over the body of his creation, the manifestation of his body of knowledge?

\section{"I WiSH TO BE AlLOWED TO SPEAK"}

When the creature acknowledges that he can control himself, but has decided not to, he demonstrates the rational, albeit cruel, decision-making free will philosophers such as Descartes and even Buffon would recognize as decidedly "human." However, no one in the novel ever considers the creature anything other than a monster, and their inability to recognize his seemingly human nature begs the question of "what then, exactly, makes a human?" The gaze dictates more than just the creature's outward appearance, for the dominant ideology's judgment forces viewers into a specific way of knowing and recognizing the body itself. When Megan Stern writes about the modern-day Visible Human Project (an online resource featuring scanned complete three-dimensional images of male and female bodies), she contextualizes this gaze as one specific way of "seeing" the human, and she raises the point that "this new scientific way of looking at the human body also raises questions concerning the integrity of human identity and the relationship between mind or soul and body" (62). We look at bodies without considering the necessary mind or intelligence behind the face, and this draws us away from 
identification and sympathy with the being, leaving us subject to a systematist's taxonomic discretion.

Victor Frankenstein consistently relies on the creature's appearance, and apart from his creator, all other characters in the novel also consider the creature's ugliness as a justification for fear and denial of a sympathetic consideration accorded to their fellow human beings. This reliance on appearance and the image of difference places Victor well within the ideology of Enlightenment discourse, and although he created this "monster," he cannot recognize it as his own offspring. In this way, Shelley is calling attention to a tendency to identify and classify all creatures, whether "monstrous" or not, and makes the argument that relying on this single-minded way of seeing and knowing living beings is what slips humans into separating our own species into groups according to superficial differences. Shelley is also commenting on the dangers of denying others a voice when considering what is "human" or not; it is curious that the female humans within Frankenstein remain the object or audience of these tales rather than the creators. As Knellwolf and Goodall remark, "In many respects, Frankenstein criticizes an attitude towards knowledge that came to be identified with the Enlightenment" (3). When he travels to Ingolstadt, Frankenstein's mother has died, and he cuts off all communication with his cousin Elizabeth, barring himself from any female intervention into his science and experimentation. In essence, when he creates, he overthrows the natural order, and grows a child without any incubation inside another body - he removes the body that encases the human.

Under the patriarchal discourse's power, the women of Frankenstein are purely objects, whether objects spoken or written to or the subjects of a masculine gaze and 
summarization. Victor characterizes Elizabeth's emotional states, nature, and temperament according to what he sees. Interestingly, when he speaks of her, he compares her to a "lower" being, whether noting that she "was docile and good tempered, yet gay and playful as a summer insect" or that "her person was the image of her mind; her hazel eyes, although lively as a bird's, possessed an attractive softness" (20). Her beauty serves as an indication of her personality, for her "open and capacious forehead gave indications of a good understanding" (53). Even though Victor apparently accepts that she has an inner intellectual life, he drifts back to considering her something lower than himself, because "While I admired her understanding and fancy, I loved to tend on her, as I should on a favorite animal” (20). We do see glimpses of Elizabeth's mind, however, and these hints suggest that Elizabeth may have had more to say than we hear from Frankenstein and Walton's accounts. When no one will speak on Justine's behalf during her ill-fated murder trial, Elizabeth reportedly says "when I see a fellow-creature about to perish through the cowardice of her pretended friends, I wish to be allowed to speak, that I may say what I know of her character" (56). Apparently, Elizabeth, though understanding, was jealous of Victor's opportunities, for when he leaves for his second tour away from Geneva, she "approved of the reasons of my departure," but she "only regretted that she had not the same opportunities of enlarging her experience, and cultivating her understanding" (110). Elizabeth is the object of Victor's gaze, and her position as an active subject is sifted through the masculine narrative, kept within the hierarchical table of what has been named as occupying a "lower" position on the ladder of civilization. 
Because Victor's creature is never named, we are left unsure of his status, but the narrative points to an overwhelmingly sympathetic being. Our difficulties lie in the narrative itself - we cannot see the creature - the creature must exist in our minds, precisely where the novel's characters do not seem to want to look. The focus on the body within Frankenstein only reveals the creature's outward status as not human, and, in Descartes's terms, a mechanical being, so we are barred from seeing past the body into his potential humanity. When we prioritize "human" over the lowly mechanical creatures, "Shelley forces us to ask what else we lose sight of when we veil our own status as mechanical organisms" (Engelstein 197). Victor abandons his stated goal of re-creating a human being early in his experiment, but his vow to create a being that is an improvement fails to take into account a vital part of the human being.

When mired specifically within the dominant discourse, Frankenstein focuses on the image and classification of his creature, rather than considering the mind or "soul" of the being, and also ignoring his need for care and education into "civilized" human behavior. Even though the creature might, at least at first, look like a human and move like a human, ignoring the development of the soul, or, as Descartes might describe, the regulation of the pineal gland, will not result in the ability to be human. But, as philosophers were quick to point out, the physical appearance does not make the man, and the question of human nature and the existence of a soul remains an ever-present conundrum. The creature, unnaturally created to be a species superior to humans, crosses the barrier of humans and animals, but also bars Victor from his fellow-creatures. Frankenstein's resultant “monster" develops because Victor has denied the creature any 
semblance of "natural" reproduction, and therefore remains incomplete and only an inaccurate "imitation" of a human.

\section{The Creature’s Body, Part II: The Severed Connection}

Frankenstein's creation uses language and reason to convince Victor to construct a companion; the creature uses the most civilized, "human" method available to him, and at first, Victor is moved to consent. This success sheds light on what we could consider the creature's double nature of both a physical, bodily monster and a civilized human able to overcome animalistic instincts and control his passions in order to logically argue his case. The creature employs methods that raise him to be worthy of the same consideration as any of Frankenstein's fellow-creatures, and plays upon what Engelstein characterizes as "a thinking and emoting machine, a rational animal" that "unearths uncomfortable truths about humanity, revealing our proximity to both machine and animal, and the subjection of our subjectivity to nature" (183). The creature highlights the growing unease and crumbling boundary between humans and non-humans, and this uncomfortable "proximity" helps to explain Victor's decision to first help the creature, and later to hinder him. Just as countless subsequent readers do, Victor can't seem to make up his mind about the creature, and as Josh Bernatchez has described, at this point in the narrative Victor is caught in "the contrast between the Creature's 'excellent qualities' (human), which would endear him to social beings, and his degraded (animalistic) state" (208). However, no matter how compassionate and sympathetic Victor feels toward the creature, when he again prepares to compose the female of the 
species, his focus moves away from sensibility and reason, and moves back to a focus on the body - and this time, the female body.

The renewed attention to the creature's body concludes the novel's focus on reason and sympathy, and also marks Victor's conversion away from any type of partnership or compassion for his creation. Even before he begins to assemble the female creature, his disgust breeds a type of procrastination that reveals his ignorance of female composition: "I feared the vengeance of the disappointed fiend, yet I was unable to overcome my repugnance...I found that I could not compose a female without again devoting several months to profound study" (107). The ignorance and procrastination spreads to his own life, for he himself cannot take a mate until his task and study is complete, for, as he exclaims, "Alas! to me the idea of an immediate union with my cousin was one of horror and dismay" (108). In contrast to his first creation, which was completed in zeal and the excitement of discovery, his new task is akin to slavery, and Victor sees himself forced to obey the whims of that which he allowed to tower over him, describing himself as a "slave of my creature" where he had "allowed myself to be governed by the impulses of the moment" (110). Suddenly, the roles are reversed - the creature is the powerful, superior being, and Victor is the lower animal, without power over his instincts and passions, forced into the female role of the reproducer.

When Victor begins to gather his "materials" for the creation of the female, he realizes that what he had done and would do again was an egregious crime against his own species, or "fellow-creatures," as he often remarks. When he reflects on his new being, he "felt as if I had committed some great crime, the consciousness of which haunted me" (116). Victor senses his unnatural appropriation of female reproductive 
power; an investigation of Shelley's linguistic choices in this passage will prove instructive. When in the British Isles with Clerval, Victor retreats to a land characterized as dead and barren, conveying the inadequacy of the male's ability to properly nourish and develop a child. The Orkney Islands are described as "hardly more than a rock," and having "soil that was barren" with the "want and squalid poverty" of "the stony beach of the sea" (117). His disgust at creating the female lingers as a long term of birth, where he "proceeded in my labour, it became every day more horrible and irksome to me" (118). But when he takes the time to think about the possible consequences of creating a female, he begins to realize that the prospect of being the benefactor a new species may not be a desirable outcome. In this fury of horror and fear, Victor "tore to pieces" the new creation (119). Throughout this passage, Victor Frankenstein never considers the female creation a human being. Even though the pieces were most likely composed of human organs and body parts, "the remains of the half-finished creature, whom I had destroyed, lay scattered on the floor, and I almost felt as if I had mangled the living flesh of a human being" (122 [my emphasis]).

As Victor describes his fears stemming from this new, female, and undoubtedly ugly creation, a large part of his horror hinges on the agency that this new female will wield. Even though the creature assures Frankenstein that she will be peaceful and a companion to himself, Frankenstein fears the power of a woman that was not born into or under the ideological purview of the dominant discourse. In other words, the female might resist this way of knowing, and choose her own narrative path: "she, who in all probability was to become a thinking and reasoning animal, might refuse to comply with a compact made before her creation... she also might turn with disgust from him to the 
superior beauty of man" (118-19). In addition to her possible autonomy, the female's power of reproduction may prove to be disastrous for human beings, and that a new race of "devils" would "make the very existence of the species of man a condition precarious and full of terror" (119). Once again, the appearance of a creature takes over, and wakes him into the real consequences of his actions, when he notes, "I now felt as if a film had been taken from my eyes" (122). The prospect of hybrid human-monsters is indeed frightening for Frankenstein, just as rumors of human-ape hybrids frightened naturalists because of their indefinable natures. As Mary Jacobus explains, appearances and the female gaze might be influential in her own choices, and we can hear hints of the possible return of the hybrid creature: "The threat to male sexuality lies not only in her hideous deformity, refusing to accommodate the image of his desire, but in the dangerous autonomy of her refusal to mate in the image in which she was made" (103). The female almost-creature poses a resistance more dangerous than the male creation, for the reason of not only her procreative power but also the power to influence an ideological shift away from the contemporary model of female and male classifications and "places" in society. This signals where Shelley's resistance to a singular, male-dominant way of knowing lies - the denial of the female and female intervention disturbs the creature's ability to be seen as anything other than a monster - and can only now be classified as an aberration, and not human.

At Frankenstein's gruesome destruction of the female creation, we begin to see what I am terming Shelley's resistance to the classifying discourse. When he destroys the female body, and, in consequence, any possibility of reproduction, Victor realizes the error of his ways throughout the entire preceding action, and as this "film" disappears, he 
understands the barrier his work erects. Victor had removed himself from social connections and interactions while creating both creatures, becoming himself an impotent and ineffectual human who may be hindering his fellow creatures. However, while creating his beings, before he destroys his female creation, there is a division between the dominant discourse and the female discourse or "way of knowing" that he occupies. The creatures and the creation of them pose a barrier between Victor and his participation in human society: "Company was irksome to me; when alone, I could fill my mind with the sights of heaven and earth... I saw an insurmountable barrier placed between me and my fellow-men" (113). By attempting to supplant reproduction, and in turn reject the female role in creation, Victor retreats from the social aspect of humanity, and his literal physical separation from society can been seen as a figurative severed connection between himself and his human fellow-creatures. As Victor narrates, "I left the house, the horrid scene of last night's contention, and walked on the beach of the sea, which I almost regarded as an insuperable barrier between me and my fellow-creatures; nay, a wish that such should prove the fact stole across me. I desired that I might pass my life on that barren rock" (121 [my emphasis]). Victor's rejection of his creature's ultimate request for a mate and the possibility of companionship in many ways reveals his rejection of other sources of knowledge or ideologies of power. However, when he gives up his efforts, the "film" of the feminine discourse of reproduction disappears and Victor becomes fully ensconced in the masculine tradition, losing all sympathy for the creature. Victor once again returns to the classifying, dominant discourse of power; he leaves the barren land and returns to the world of men after he rejects this reproductive mindset, and after he sleeps, he is able to re-enter the human fold, noting that "when I awoke, I again felt as if I belonged to a race 
of human beings like myself" (122 [my emphasis]). And when his ship returns from the island, he finds himself "suddenly transported back to the neighbourhood of civilized man" (124).

These breakages and mends, and Victor's severance and re-animation in the society of civilized men, represent the dangers of considering discourses outside of the normalized, dominant, classifying knowledge. Yet Shelley resists this seemingly peaceful resolution and pushes back against the singular, male-dominant way of knowing, for the male creature still lives and still wreaks havoc on Victor's life. Rejected by humans, the creature acts against humanity, and any semblance of a soul or compassionate nature, as Descartes would have us believe is the touchstone of human difference, seems to disappear after his murder of Henry Clerval.

\section{Human Passage}

Frankenstein's creature cannot be classified as "human"; however, because the creature is composed of human parts yet seems so "animal," no one who encounters him can name or identify exactly "what" he is. Victor's confusion and fear on coming home after creating the creature reflects his uncertainty: "Fear overcame me; I dared not advance, dreading a thousand nameless evils that made me tremble, although I was unable to define them" (48 [my emphasis]). The unknown is frightening and monstrous, and when unable to name and classify this creature within the familiar conceptual ordering framework, the creature becomes something evil and terrifying, the hybrid monster. As we see in the image of Victor gazing wide-eyed at his creation (Fig. 9), the creature, even though surrounded by emblems of the classifying discourse (the skeleton's 
body and the written word), remains incomprehensible, and appears to unnerve both

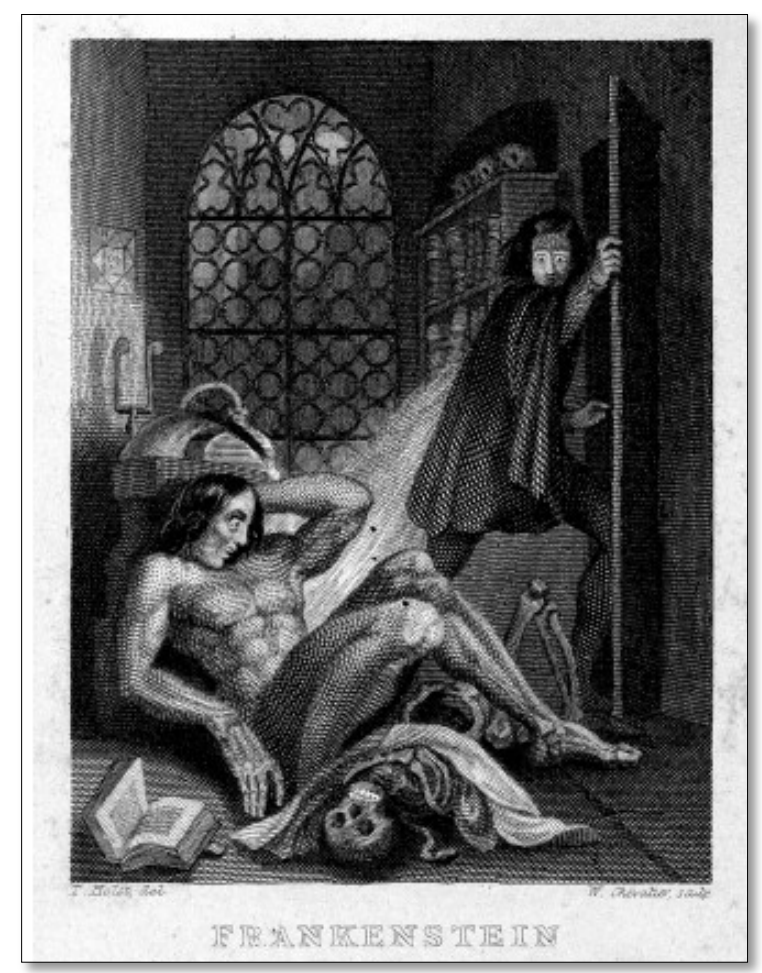

FIG. 9. Victor sees his creature gazing upon himself. Wellcome Library. figures. The creature, being educated within this framework, cannot identify himself either, so he attempts to place himself within some familiar narrative, but understands his tenuous analogy, as he equates his situation to that "Like Adam, I was created apparently united by no link to any other being in existence; but his state was far different from mine in every other respect. He had come forth from the hands of God a perfect creature" (90). He realizes that the similitudes end there, but after he does, becomes

despondent: "no Eve soothed my sorrows, or shared my thoughts; I was alone. I remembered Adam's supplication to his Creator; but where was mine?" (91-2). The creature has no Eve, but he also has no mother.

While many feminist critiques of Frankenstein have commented on the creature's lack of a mother and his ensuing confusion and inhumane behavior, the overwhelming conclusion and blame seems to lie in Frankenstein's choices and attempts to usurp the feminine power of reproduction. When Deborah S. Wilson comments on Victor's appropriation of all reproductive power, she notes that Frankenstein is "a critique of the 'masculine' scientist's relationship to a 'feminine' nature" (190). As a comment on 
science and technology, "Shelley implicitly argues no matter how sophisticated the medical technology, maternity - even procreation itself - can never really become solely male" (Wilson 108). I will not argue with these points; Shelley is warning against a full removal of the female from biological reproduction. However, I would additionally argue that Shelley is warning that although medicine and science are advancing at an astonishing rate, prioritizing one mode of understanding those advances to the removal or detriment of other forms of knowledge, or other populations' knowledge, can lead to dangerous consequences for all of the natural world. This singular understanding, the classifying discourse, attempts to place everything unknown within a framework of rank and order, and does not allow for interpretation or consideration of those beings seemingly "outside" of the table. Frankenstein's lack of female speakers is not inconsequential; their silence is so deafening that we have no choice but to hear them. In this way, Shelley calls our attention to the missing female perspectives, and we immediately notice the creature's missing female progenitor.

Mary Shelley, herself a mother at the time of Frankenstein's creation, and writing at the beginning of a period which holds Nature and its sublimity in the highest regard, wants to move beyond the single discourse of science as a masculine and unfeeling categorical tool. She gives us this "creation" story to warn against the humanity that we as humans lose when we see ourselves as separate from or perhaps better than all other natural beings. Shelley uses the discourse to her own ends, and resists the idea that science, and the men who practice it (as most women were barred from being scientists), will be the creators and future producers of all knowledge and understanding. She is not resisting science, but rather the way that science was accorded all power. Ellen Goldner 
describes Shelley's resistance as not rejecting all European culture and science, but rather as reiterating the importance of more than one way of seeing the world: "reworking of a discourse need not imply that it functions as either a radical or transcendent (re)vision of cultural norms" (29). As Clayton Koelb argues, Shelley uses the logic and language of Foucault's "Classical" period in order to resist it and present an alternative combination:

The act of creation associated with a rhetoric of patriarchy is reproduced here, but with that rhetoric doubled back on itself. Frankenstein may thus be understood as pushing the logic of traditional accounts of creation so far that the patriarchal perspective will no longer hold, even as it serves as the foundation for everything that happens in the story. ("I Sickened" 131)

As we have seen in Chapter 1, naturalists and philosophers often saw the body as the important and primary indicator of any animal's taxonomic classification, while the "mind," or, as some put it, presence of the soul, was what made the human so unique and singular in nature. Although separate elements, the body and soul work together to complete a human being, and Shelley recognizes and uses this point to consider how these two come together. When the creature incubates himself in the De Lacey's hovel, he observes and learns from humans, but he was never nurtured within a mother's body, and therefore has no true, deep "understanding" of what it means to be human. The power of reproduction implies the mother's influence on a child, be it their appearance or their disposition. As Goldner argues, Frankenstein shows us that the mother's body is the "body as the Other both out of which and against which it forms the soul" (30). Control in reproduction gives women their own discursive power, and gives their voices a new speaker: "women did derive from this discourse a certain form of limited power... Ironically, the discourse on monsters provided women with a means of asserting their importance in the process of reproduction" (Bewell 115). And this knowledge or new 
"way of knowing" extends from the body and soul to the text, re-creating the human via textual production and reproduction, for, as Alan Bewell writes, "Frankenstein distinctively appropriates and extends this discourse on bodily creation to all aspects of human knowledge, and especially to literary creation" (118).

\section{The TeXt, (Re)Animated}

Rather than paint Shelley's novel as a strict resistance to the dominant discourse, we must see that Shelley works within the dominant discourse of science and the classification of the creature as non-human in order to show us that considering multiple discourses, including the feminine discourse of reproduction, can open the consideration of sympathy to species other than humans. Shelley shows us how a text can rescue the body of the creature, and how the dominant discourse can be used to show sympathy and care, as if the text itself is a body that can be re-animated into a body of knowledge. In other words, a discourse connected to sympathy can rescue the inhumane in science, and can bring about a different type of classification that includes considerations of sympathy and care for all links in the Chain of Being. In Clayton Koelb's The Revivifying Word: Literature, Philosophy, and the Theory of Life in Europe's Romantic Age, he argues that Romantics' art attempted to add a spirit to an ideologically soulless discourse focused on identification and tabulation, and that their "aesthetic theory frequently presents artistic creativity as a spirit that animates otherwise dead matter" ("Introduction” 3). When Victor Frankenstein edits Walton's notes, he revises the creature's story to one of sympathy and soul: "I made notes concerning his history: he asked to see them, and then himself corrected and augmented them in many places; but principally in giving the life 
and spirit to the conversations" (151). In this way, Victor rescues of the text from a lifeless existence: "for the result of his efforts is to be a textual body saved from mutilation instead of the mutilated looking body he had produced when he made the creature" (Koelb, "I Sickened" 141). Victor seems to be aware that all anyone will see and know is the textual body of the creature, rather than his physical body, appearance, and voice. The creature's story becomes his only existence, and we see this as one in which we can sympathize. Although the creature is not human, he certainly deserves our attention and consideration.

The artistic "sympathy" that forms from the creature's textual body signals how the text takes over the physical body, and the text becomes the only indicator of the creature's (or Victor's, for that matter) humanity. The body becomes the text, the appearance we look to and analyze for signs of life. Shelley's resistance to the dominant discourse not only presents the warning of a soulless creature as the product of only the masculine way of knowing, but also gives the hope a new sympathetic body of work can offer the changing culture of public knowledge and public discourse. Catherine Waldby argues that Frankenstein's creature can offer a vision of a new social revolution, one accepting of multiple discourses and textual productions. She asserts that Shelley is asking a new question, which not only asks questions of the soul, but questions of our own place in the Chain of Being: "How does a variation on human being, not born of woman but rather manufactured through scientific procedures, stand to the human social order?" (Waldby 33). Although ultimately a failure in Frankenstein, the creature signals the beginning of human / non-human cooperation and consideration, built around sympathy and empathetic emotion (37). 
The creature's text becomes the body that we see or read, and the end of his narrative also seems to mark the end of any semblance or conversation of sympathy with him. The creature is incomplete, lacking the designation necessary for consideration within the human species, a machine without a soul. As Douthwaite remarks, the blame for the creature's unnamed and unclassified existence lies with Victor's inaction - simply put, "Frankenstein withheld the crucial care needed to humanize the monster" (222). This idea of "care," and the caretakers, or carers, comes to the forefront of Never Let Me Go, for even given their status as clones, these creatures give and receive care and remain sympathetic and seemingly "human" throughout their lives. Kathy H.'s text is her body as Bouriana Zakharieva proposes, "organic is now the technical; it is culturally constructed, not naturally given, and the body is always already discursive" (418-19). The clones' aesthetic sympathies lead readers to consider their texts and bodies as animated with the human "soul" as fully empathetic creatures.

When Ellen Goldner claims that Frankenstein "obsessively repeats the displacement of the old discourse of the body by the emerging discourse of the soul," she does so under the aegis of Foucault's argument about the regulation of power and knowledge (30). However, in the language of the "soul," or at least within the classifying discourse's rigid differentiations between human and non-human, we still see that naturalists like Buffon and Lord Monboddo never really forgot about the soul. In fact, they used intelligence and the human mind's ability to use its free will as a major piece of evidence to mark a being as "human." As we look forward to literature after Frankenstein and into Foucault's "modern" era, we can see how the discourses of power and classification have shifted to new areas. No longer are humans attempting to define all 
humans within a single "higher" species, but rather are opening new discourses that ask us to question the concept of a human "difference" and previous considerations of the "human" soul above all others. By the time we reach 2005 and the publication of Never Let Me Go, the search for the "human" soul continues, but the body is now, for all appearances, human, and so the masculine classifying discourse take on new forms and opens into new ways of knowing. However, we can still trace how Kathy H.'s text marks her as "human" through her literal text, her DNA, and her figurative body of work, her memoir. What makes someone or something a human being shifts, and tells us about how our constructed barriers are deteriorating. 


\section{CHAPTER 3}

\section{THE VIEW FROM THE OTHER SIDE: NEVER LET ME GO'S CLONES}

In Chapters 1 and 2, I described and examined examples of what Foucault termed the "Classical" period of discourse, where appearance, vision, and naming characterized the general "way of knowing" about humans and the human species. Chapter 2 outlined how Mary Shelley's Frankenstein identified the necessity of incorporating multiple discourses into an understanding how humans have constructed their place, and Other's places, in the world. In this chapter, I will discuss how this mode of thinking has changed, but remained the same. What I mean is that the scientific discourse has come to dominate our lives, yet has paradoxically allowed alternative ways of knowing within its fold, and for the most part within the Western tradition, humans consider themselves as existing in a network of connection with and within the animal kingdom. This chapter investigates how one modern novel, Kazuo Ishiguro's 2005 Never Let Me Go, reimagines what and how we consider something to be "human," but also demonstrates Foucault's assertion (or perhaps welcoming embrace) of the end of the "invention" of the human. Never Let Me Go reveals how the question of human difference extends into larger questions of how humans relate to and identify with non-humans.

In Frankenstein, the new species is never considered human, except for a few fleeting moments of Victor's early zealous fancies. In Never Let Me Go, however, the 
clones are occasionally confused with human beings, and their appearances bar any conception of outward difference. In this way, as Gabriele Griffin explains, the "copy becomes more human - that is he develops a great capacity for intimacy and reciprocal commitment"(655). The clones' abilities to both look and act like humans demand human attention and care. Their bodies are initially created for the use and benefit of human beings, but some "guardians," the clones' caretakers, see them as having souls, and not simply as machines without thought or emotion. In this way, as Shelley resisted notions of appearance dictating what could receive sympathy, Ishiguro expands the question of empathy to “other" beings. According to Griffin's argument, Never Let Me Go resists "the notion that the material is immaterial in the sense of worthless, not worthy of our consideration because beyond the grasp of a reflecting consciousness. Instead, it suggests that body and spirit are imbricated and that the material is not divorceable from its animating impulse" (656). In other words, Never Let Me Go asks what it means to be a human being, both body and soul, and asks whether human beings are the only souls worth considering.

Never Let Me Go's narrator, Kathy H., is a clone. The story takes its time revealing this, leading readers through Kathy's memories of life within Hailsham, a boarding school focusing on training in art, literature, and the humanities, preparing students to be "carers" and, ultimately, donors, who give their organs and body parts to the "normals," human beings. Carers are assigned to other clones, who they nurse through the organ donation process and work towards "completion," commonly understood to mean death. Throughout the novel, Kathy takes readers through the education, romance, and behaviors that lead to the clones' identities as artistically trained 
donors who use their memories to build the only sense of personal history that they have. John Freeman describes the novel as "imagin[ing] a world in which genetic cloning - not nuclear technology - turns out to be the defining science of the twentieth century" (62), but the novel avoids the common features of most dystopian and science fiction novels, and is written in an autobiographical style devoid of scientific language. Kathy H.'s personal narrative operates under the assumption that her readers are clones, and although we are not clones (presumably), "they" don't seem quite so different than "us" after all. Kathy H. remembers her younger days at Hailsham's boarding school, pointing to experiences and interactions that seem remarkably familiar and human, yet the lessons she learns reflect the clones' humanistic education to foster empathy and emotion, recognizing the way humans, the "normals," are afraid or uncomfortable around the clones, and the clones' concerns that their artwork will not be adequate reflections of their souls. Upon completing their work at Hailsham, the students are transferred to smaller houses, where they live in groups resembling family units, training the teenagers to "perform" as human adults. The experiences during this phase in the clones' lives recount their search for not only meaning, but also where they came from - their search for Ruth's "possible" human genetic mother leads to a dead end. The final section of Kathy's narrative follows the end of her carer career, when she reunites with her friends Tommy and Ruth, nursing them through their donation (and death) processes, including a tragic disappointment for Tommy and Kathy where Kathy resigns herself to donation and subsequent bodily fragmentation.

There is no question that the novel presents cloning and biotechnological concerns of the early twenty-first century, however, many critics and readers were 
confused by the novel's lack of scientific language and style. Several critics defend and contextualize Ishiguro's novel by pointing out cloning's relevance, such as Steve Garlick: "As an exemplary representative of contemporary biotechnology, cloning finds itself always already given over to the non-scientific. Its meanings proliferate well beyond the laboratory" (140). The clone unsettles us, because we cannot rely on simple distinctions of appearance and manner, and forces us to think about the long-held values of humans as the top of the Chain, for, as Garlick goes on, "[h]uman cloning holds the threat of disrupting humanist discourses that are grounded in a belief that the freely-given generation of the human produces a natural order of life" (141). By making the novel about clones but also "authored" by a clone, we must reconsider the qualities and definitions we hold as integral to the human difference, and by "confronting us with a literary fabrication such as Kathy $\mathrm{H}$., Ishiguro forces us to probe the essence and

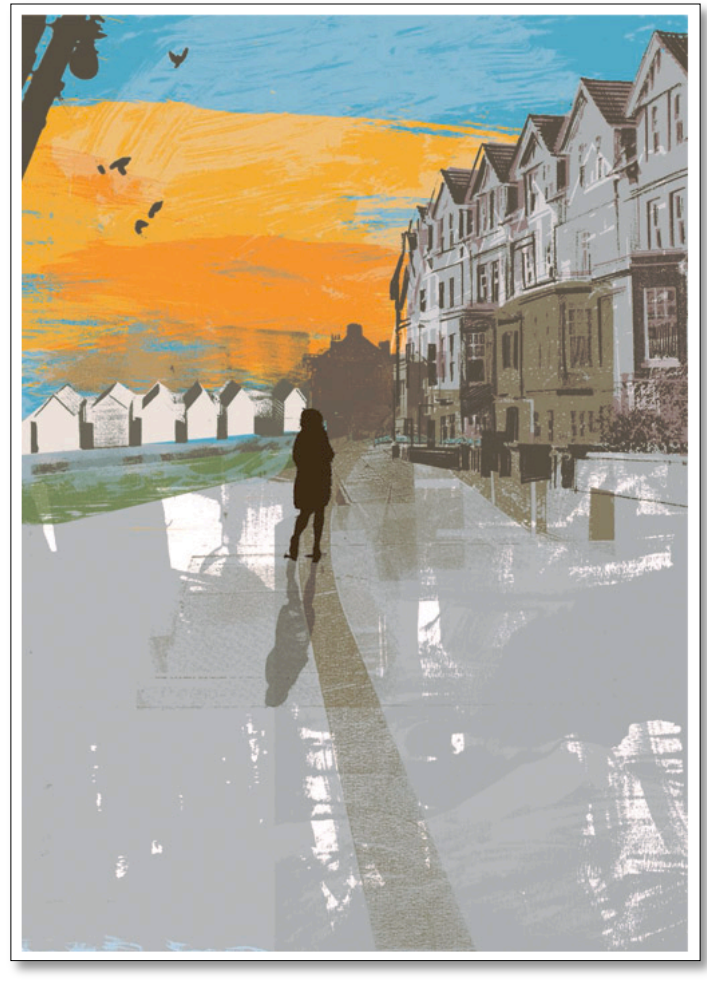

FIG. 10. Kathy H. walks the barrier. Folio Society. the limits of humanity" (Puchner 36). As Ishiguro himself describes, "[b]y making them clones, we're actually raising the issue of what human nature is" (James 39). The novel's clones fit the Enlightenment naturalists' definitions of what outward appearances and features qualify as "human." Kathy's narrative demonstrates her mastery of human discourses and adds another, the non-human discourse. However, the novel complicates 
the definition by asking how Kathy's narrative calls into question, as Ishiguro himself has asked, what makes us human? Kathy H.'s appearance and form make her indistinguishable from the "normals" (Fig. 10), but she occupies the line between human and non-human, a silhouette of one (human) and a shadow of another (non-human). Ishiguro's question extends far beyond the question of a clone's potential status as a human being; his novel questions the construction of a human difference, the barrier of human / non-human. Ishiguro reminds us and describes why he chose to use clones, saying, "I was always trying to find a metaphor for something very simple - it sounds rather grand - but, a metaphor for the human condition" (Wong and Crummett 215).

\section{RE-NAMing Humans}

Kathy H. communicates her understanding clearly, and throughout the narrative we empathize with her emotions and reminiscences. These myriad little understandings call back to Annette Kolodny's "Dancing Through the Minefield," where she describes how literature and writing use embedded social codes and traditions, the "mental artifacts of the society from which it comes" (4). Because we read and identify with Kathy's memoir, we understand and identify with the clones. Martin Puchner confirms this when he remarks that in Never Let Me Go, "the teenagers have a keen interest in and a sharpened sense for social codes; small gestures and seemingly minor comments take on great significance" (35). From the beginning of her memoir, Kathy calls readers out as clones themselves, presenting us with what could be a translation error - yet we read the text as we could any human memoir. When, as Puchner argues, "Kathy H. slyly addresses the reader as another clone" (46), she is consciously pulling readers into her own point of 
view, knowing that if we can empathize with clones, we are much more likely to alter our behaviors towards those who are different. Kathy speaks to us as if we were her fellowcreatures, speaking of how the clones at Hailsham were able to sense that they weren't like their human guardians: "we were just at that age when we knew a few things about ourselves - about who we were, how we were different from our guardians, from the people outside... I'm sure somewhere in your childhood, you too had an experience like ours" (36). She does this often at the novel's beginning, before the word "clone" is ever mentioned, and so by the time we know their true origins, we have already taken a clone's point of view. This troubles the divide so staunchly constructed by naturalists and others who insist on the human difference and superiority - for, if we can empathize with clones, what other species and "lower" orders are perhaps less "different" than previously believed?

Kathy H. presents her readers with numerous pieces of evidence that would lead us to classify her as a human, both in appearance and behavior. She starts out her memoir with her 'name,' calling attention to it so that we humanize her immediately at "My name is Kathy H.” (3). She remarks about her instincts and knowledge of care for her fellow creatures: "I've developed a kind of instinct around donors. I know when to hang around and comfort them, when to leave them to themselves" (3). At Hailsham, the clones were trained and educated to be civilized and to take up the same demeanor as their guardians, as the "guardians were always telling us to be civilised" (7). Several of the scenes during Kathy's Hailsham narrative recount what most would classify as childhood behavior and discoveries, but there always seems to be a shadow of doubt hovering within the stories. 
By subtle cues, Kathy H. gradually leads us into the realization that these children are not human as we understand the term.

As Kathy describes the lessons they received in the school, the students begin to realize that they are not the same as their guardians. At one point, the guardians instruct them to take care of their health, to retain their bodies' viability: "And then there were the actual lessons where they showed us horrible pictures of what smoking did to the insides of your body...'But what you must understand is that for you, all of you, it's much, much worse to smoke than it ever was for me"” (68). The clones think about each other as fellow creatures, but they slowly realize that they did not develop the same considerations for the guardians, and Kathy suggests that the guardians encouraged this separation, noting, "We'd been taught to think about each other, but never about the guardians. The idea the guardians had differences between them, that never occurred to us" (89). As the students grow older, the division is more explicitly laid out, and they are trained to act as human beings, so to not raise too much attention. Their "Culture Briefings" prepare them for a life outside Hailsham, and these "were classes where we had to role play various people we'd find out there" (110). They were even told that their behavior "outside" needed to blend in with the normals, or humans, especially when it came to matters of relationships and sex: "people out there were different from us students: they could have babies from sex...And even though, as we knew, it was completely impossible for any of us to have babies, out there, we had to behave like them" (84 [my emphasis]). In a way, the clones were creating a classification system for the humans that they encountered, giving them their own names, from "normals" and "guardians" to the doctors being called "whitecoats," just as Miss Emily re-named the clones "students." This impulse to name 
and classify demonstrates Kathy's use and mastery of the classifying discourse, but also her perhaps human impulse to name and understand those she sees as different or Other. Kathy simultaneously uses and overturns the dominant discourse she has mastered; she is the definition of a human being, body and mind, but the "normals," the humans, in the novel still do not find her to be human. Something seems to be missing; yet no one can identify that "something." Even the guardians of Hailsham, who dedicate their lives to proving that the clones should be considered human, are still unconvinced of their natures. Questioning the status of the clones leads to questioning the status of the human, or, as Puchner states, by "including us in this world of clones, Ishiguro forces the reader to question the essence and the limits of the human" (49). Not only do we seek the special unifying piece to equal "human," but we must find the smallest element of the human that, when removed, no longer makes the human a "human."

Hailsham's grand mission, revealed by the former headmistress Miss Emily at the novel's end, was to change the way that humans perceived and treated the clones. These changes include not only the clones' education and artistic training, but the changes in names and classifications were somehow supposed to change the nature of the way humans saw the clones. As Miss Emily recounts, “'Together, we became a small but very vocal movement, and we challenged the entire way the donations programme was being run. Most importantly, we demonstrated to the world that if students were reared in humane, cultivated environments, it was possible for them to grow to be as sensitive and intelligent as any ordinary human being"' (261). Before Hailsham, the clones were seen as only supplies, storehouses of body parts and organs for human consumption: “'all clones - or students, as we preferred to call you - existed only to supply medical science. 
In the early days... that's largely all you were to most people. Shadowy objects in test tubes"' (261). Even within the novel's time period, the clones have risen from the lower, shadowy depths of the Chain of Being to an almost-human distinction, which would itself beg the question of where humans now stand if other beings are to be seen as similar and less different than previously thought.

These ideas move the human, and the human distinction, forward in Foucault's timeline of his archaeology of human classification - the clone's narrative is Foucault's "shift" realized. As Foucault sees it, the period of thought that "made it possible for the figure of man to appear" was due to changes in the ways of knowing that had previously dominated. This "invention" of what we would classify as human, which Foucault's archaeology shows has only recently existed, is "perhaps nearing its end" (Order 386-87). Never Let Me Go offers us fictional waypoint in Foucault's archaeology, for its clones shift the boundary of the human and also represent a larger consideration for non-humans and Others that we would previously have determined as "lower." And yet, the novel does not always celebrate this change. When Kathy and Madame discuss a scene from their past and Kathy asks her why she was crying, Madame tells her that she was weeping because of the death or end of the old way of knowing things, and the harsh realities that would emerge: “"When I watched you dancing that day, I saw something else. I saw a new world coming rapidly. More scientific, efficient, yes...But a harsh, cruel world. And I saw a little girl, her eyes tightly closed, holding to her breast the old kind world, one that she knew in her heart could not remain"” (272). 


\section{KATHY H.'S NEW DisCOURSE}

As previously mentioned, Kathy uses what she was taught at Hailsham to draw humans into the clone's discourse, or insert her narrative into the conversation. Kathy uses the human discourse of knowledge to her own ends, which relates to Donna Haraway's call for a feminist discourse of science: "We have not set the original terms of discourse; that fact determines our texts. What are the degrees of freedom for feminist reshaping of the production of science?” (“In the Beginning” 476). Just as Haraway urges feminists to use the "terms of discourse" to their advantage and their own focus, Kathy appropriates the "human" discourses of classification and empathy to show her audience the clones' humanity and press for their place in the human's ethical consideration. The memoir or autobiographical style draws us into the clones' point of view, and, as Keith McDonald asserts, autobiography can focus on relating experiences in a narrative to build a relationship, or "creat[e] a rapport between [the] reader and writer" (75). However, as a range of fictional first person narrators have represented a non-human viewpoint before her, Kathy adapts the genre to her own needs; as she herself cannot be classified as strictly human, "Never Let Me Go is a novel that utilizes many of the techniques of the autobiographical memoir, while simultaneously barring itself from classification as an example of this genre" (McDonald 75). McDonald's commentary makes an explicit connection between Frankenstein and Never Let Me Go; he comments on how the nonhuman "creatures" capture human attention, because although Frankenstein's creature is "[r]educed to begging to be heard, the creature nonetheless gains an audience within the text” (81). Kathy employs Haraway’s method, "reshaping” the discourse for her own goal 
and giving birth to herself and the memory of the clones in text, just as the novel's humans created her body for their own purposes.

As Shelley uses the feminine discourse of reproduction to resist against the dominant discourse of classification, Ishiguro's creation, Kathy, harnesses the power of reproduction in the only way that she can to give the clones a human story. Kathy's reproduction occurs via text rather than her body; her narrative lasts about eight months, as she notes, "they want me to go on for another eight months, until the end of this year" (3). Kathy's narrative includes several references to the fact that the clones cannot have babies, but she also describes enacting motherhood, such as when she listens to Judy Bridgewater's "Never Let Me Go": "what I'd imagine was a woman who'd been told she couldn't have babies, who'd really, really wanted them all her life" (70). Kathy describes these drives as unconscious, but sees her actions as mourning the children she didn't know that she could not have, because "I hadn't known back then...that none of us could have babies. It's just possible I'd somehow picked up the idea when I was younger without fully registering it, and that's why I heard what I did when I listened to that song" (73). These references to reproduction and caring for children draw the reader into Kathy's narrative, where she uses the feminine discourse to create a new conception of the clones' inner lives.

In addition to using the feminine reproductive discourse, Kathy's narrative uses some of the same descriptive techniques as the classifying discourse, but turns them around, doing the opposite of what is expected. Rather than being classified according to appearance, the clones are classified by mood: "hardly any of them [the donors Kathy cares for] have been classified as 'agitated,' even before the fourth donation...But it 
means a lot to me, being about to do my work well, especially that bit about my donors staying 'calm'” (3 [my emphasis]). In contrast to Frankenstein's bias towards appearance, Kathy's descriptions reveal her disregard for appearances as indicators of personality. She points out the error of thinking that way when she describes Miss Lucy's image, as she says, "Miss Lucy was the most sporting of the guardians at Hailsham, though you might not have guessed it from her appearance" (26). However, although Kathy sees the folly in relying on appearances to determine one's character, the clones seem to understand that the dominant discourse does still practice this, in a way, and they practice “imitating" and copying human behaviors.

As Kathy H. looks back, she remembers that, in their days at the Cottages, the small groups they lived in as they finished at Hailsham but before they were ready to train to become carers, the clones refined their behaviors to fit in with the humans they would encounter in their few remaining years. They learned relationship behavior from humans, but rather than adopting the behavior from their social groups, they were copying and imitating behaviors from television. Kathy "began to notice all kinds of other things the veteran couples had taken from TV programmes: the way they gestured to each other, sat together on sofas, even they way they argued and stormed out of rooms" (121). And the younger clones, like Kathy's friend Ruth, picked up these behaviors from the veterans. But when Kathy speaks to Ruth about it, she points out that television culture was not the place to look for behavior, saying that "It's not something worth copying" and that "It's not what people really do out there, in normal life...It looks daft, the way you copy everything they do" (123-24). Kathy even loses her temper with Tommy when she could tell that he wasn't acting well enough to fit in with the normals: 
“'Tommy, you look so stupid, laughing like that! If you want to pretend you're happy, you don't do it that way! Just take it from me, you don't do it that way!"” (106). Their worth is measured by their ability to copy others, but also hinges on their education and culture, where Kathy recounts how "[i]n those early months, we'd somehow developed this idea that how well you were settling in at the Cottages - how well you were copying - was somehow reflected by how many books you'd read" (123 [my emphasis]). The clones' copying may, on the surface, seem like Buffon's description of Le Jocko's imitation, but when Kathy talks of the emotion behind "pretending" that the clones are happy, we understand and empathize with their point of view.

\section{A Human(ISTIC) Education}

Similar to Frankenstein's creature, the clones (and their guardians) believe that an education in humanistic or Romantic subjects will give them the inner qualities and attributes necessary to prove their human souls. When Ishiguro describes the setting he chose for the clones' education, the boarding school, he remarks on the way that a discourse or way of knowing can be controlled: "It's a situation where the people in charge can, to a large extent, control what the kids know and don't know" (Hunnewell). This gives the students background in being human, or at least what the guardians think make a good "human," where, again, Ishiguro comments that the "teachers at Hailsham did have an ulterior motive. They deceive the students, but gave them something better, not to be better donors, but to be better humans" (Wong and Crummett 219). Yet Kathy's narrative seems to also point out the difference between humans and clones, wherein Puchner identifies that "while the school's humanities education is supposed to produce 
or shape humans, these students are simultaneously made to recognize that they themselves are excluded from humanity" (38). When students were scolded, Miss Emily would always remind them that they were "special" because they were Hailsham students, and, as Kathy recounts, "[h]er general drift was clear enough: we were all very special, being Hailsham students, and so it was all the more disappointing when we behaved badly" (43). Their art and creativity was tied to their self-worth, because "how you were

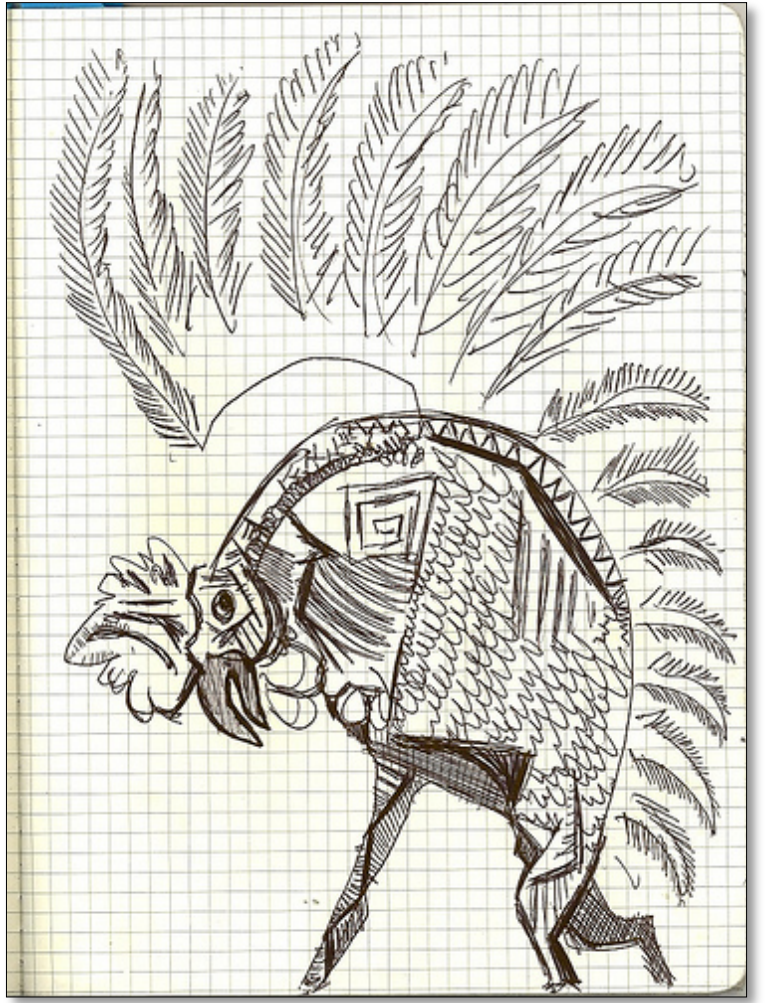

FIG. 11. Tommy's art. From the 2010 film version of Never Let Me Go. regarded at Hailsham, how much you were liked and respected, had to do with how good you were at "creating"” (16). The students' creativity connects to the rumors that drive Kathy and Tommy to later apply for deferral, where they believed that their art would reflect their souls and their capability to love.

Throughout his time at Hailsham, Tommy has trouble creating art, and he goes through various phases of frustration and anger because of it.

When he is not producing art, he feels as though he is inadequate, and he lashes out at classmates in uncontrollable rages. However, his behavior and demeanor changes after Miss Lucy tells him that he shouldn't feel bad about not being creative. Tommy becomes calmer and more introspective, and his friendship with Kathy develops into a lasting mutual fascination with the guardians' behavior and attitudes. When Miss Lucy reverses 
her previous position and tells Tommy that his art does matter, she is less than forthcoming with her reasons: “'Listen, Tommy, your art, it is important. And not just because it's evidence. But for your own sake. You'll get a lot from it, just for yourself'” (108). This feeds into the rumors that art is an indicator of the particular clone's souls, and what is in their souls. The question of the clones' souls reveals the novel's preoccupation with human nature, and the education in the humanities that the clones undertake seems to suggest that the guardians of Hailsham believed that these subjects are what define "human nature," and that training the clones in these topics would present a "more human" clone, where the learning would produce a human soul. However, as in Frankenstein, a Romantic education does not immediately cause the viewer to see the subject as "human." As Shameem Black comments, "this interrogation of what it means to be human emerges through a critique of Romantic-inspired assumptions about aesthetics and empathy" (785).

Even though the clones are led to believe that their educations and sensibilities will produce and instil empathy for them within the human "normals," the normals are not quite so easily convinced. When Black compares Never Let Me Go's clones to Frankenstein's creature and their capacities to elicit the impression or prove the presence of the soul, she remarks that in contrast to Frankenstein, which attempts to reveal the creature's soul by presenting his inner life, when the clones believe they are Romantically revealing their "inner selves" and souls, in actuality they are valued for their organs and body parts, their literal “inner selves” (794). Deborah Britzman also points out Kathy’s mis-reading of the qualities that compose the human soul, where she "patches together the romantic dream that art is an expression of the artist's soul...she reasoned, her wish 
for recognition must also reflect her humanity" (315). When Tommy recalls the way that Miss Emily handled a certain disagreement at Hailsham, where the students' art was being taken away without compensation, he remembers that even certain guardians also believed this: “"What she told Roy, what she let slip, which she probably didn't mean to let slip, do you remember, Kath? She told Roy that things like pictures, poetry, all that kind of stuff, she said that they revealed what you were like inside. She said they revealed your soul" (175). As the rumor of deferrals gains ground, Kathy and Tommy begin to focus on how "art bares the soul of the artist" (254). Even Madame, when hearing their request for deferral, repeats this, but she does so in a mocking way, which gives the impression that the even the previously believing humans no longer see this: "'Because of course' - Madame cut in suddenly - 'your art will reveal your inner selves! That's it, isn't it? Because your art will display your souls!"” (254). When Madame realizes that they are serious about their request, she addresses them not as humans, but as “"Poor creatures. What did we do to you?'” (254). Even with all of their humanistic and humanlike training and education, the clones are still barred from human status.

\section{THE BARBed Wire FenCE}

Although the clones and certain humans feel that the Hailsham students have souls, and that their art reveals these rich inner lives, there is still a barrier and humans exhibit fear when in the clones' proximity. Kathy recounts a conversation with Miss Lucy about the barbed wire fence that separates Hailsham from the open woods, and Miss Lucy suggests that there are strict divisions constructed to keep the clones away from living a normal life and from "mixing" with the normals. When Kathy and Tommy meet 
with Madame and Miss Emily to request that their terms of donation be deferred because they are in love, and when their request is denied, Kathy is incredulous. She demands to know the reasons that the guardians bothered to educate them as humans: "Why train us, encourage us, make us produce all of that? If we're just going to give donations anyway, then die, why all those lessons? Why all those books and discussions?'” (259). From Miss Emily's suggestions, readers are led to believe that many humans feel that the clones do not have any inner life, no souls at all, and when she replies to Kathy, she repeats her reasoning, saying, "'You said it was because your art would reveal what you were like. What you were like inside. That's what you said, wasn't it? Well, you weren't far wrong about that. We took away your art because we thought it would reveal your souls. Or to put it more finely, we did it to prove you had souls at all"' (260). When Kathy replies, “'Did someone think we didn't have souls?'” we see that Kathy assumes and feels that she has always had a soul, and didn't realize that the "normals" never thought that they were fully human. Yet, as Miss Emily responds, even after their work at Hailsham to present artistic, soulful clones, “it's still not a notion universally held"” (260). The barriers between humans and clones still exist, and educating the students may have taught them how to "imitate" humans, but just as Buffon's Le Jocko was only imitating human behavior, the normals see the clones as mechanistic, Cartesian animals. Interestingly, Ishiguro includes a discussion of the Cartesian machine within the novel, and this presentation brings back the debate between human emotion and motivation versus animal imitation and replication. When Kathy describes her carer seniority, having been a carer for years beyond the normal span, she mentions that she wants to be with her own kind, but also calls attention to her need to dispel ideas that 
clones are machines: “Carers aren't machines...So when you get a chance to choose, of course, you choose your own kind. That's natural" (4). The language Kathy uses often calls attention to the non-human clone, such as when Tommy's angry outbursts and inability to control his passions gets him labeled as a "mad animal" by Ruth (12). The centerpiece of Ishiguro's Cartesian discussion, however, relies on the animals that Tommy draws when he begins to create art again at the Cottages, after their group has left Hailsham. Tommy's “creatures" are composed of small, connecting parts, as if he is taking each part of the animal and weaving them together into a finely tuned machine. The scene where Tommy first shows Kathy his animals deserves particular attention. In addition, while

Tommy's drawings are glimpsed only briefly in the 2010 film version of Never Let Me Go, it is intriguing to see stills based on the text's discussion of art and to realize that the movie's

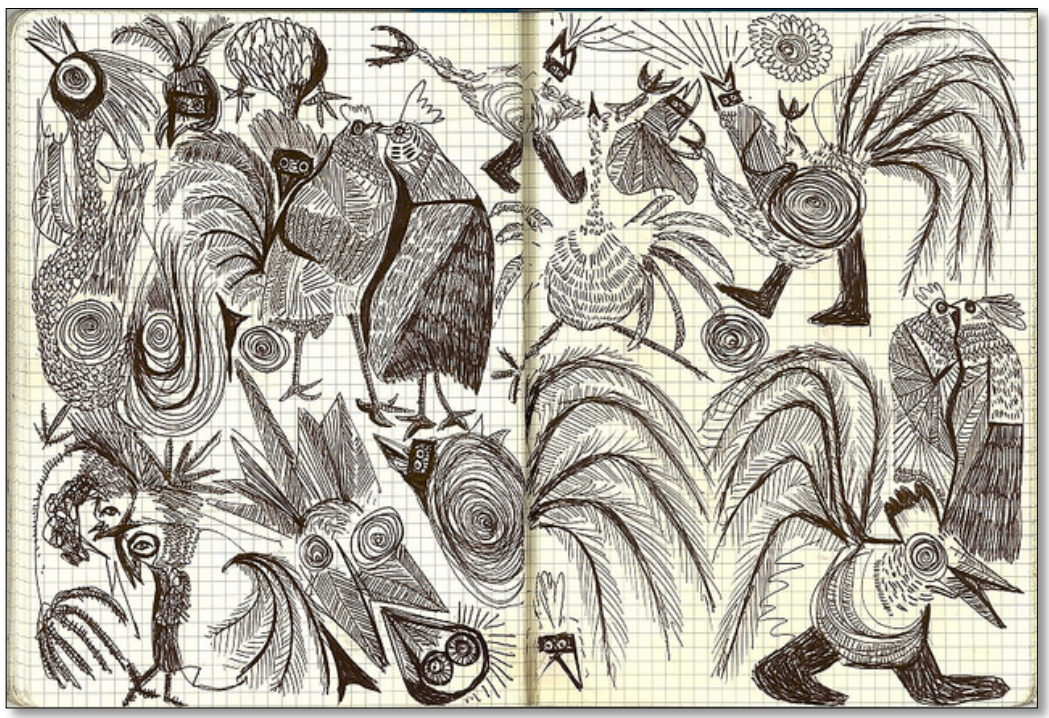

FIG. 12. Tommy's art. From the 2010 film version of Never Let Me Go.

set designers produced a credible interpretation of Ishiguro's prose (Figs. 11-13).

Although Tommy gave up on his artistic training fairly early, his return presents not only his hope for a reprieve from donations, but also his chance to prove his humanity. Kathy, however, does not know how to classify the art, because she hasn't been trained in this discourse: "what I was looking at was so different from anything the guardians had 
taught us to do at Hailsham, I didn't know how to judge it" (187). This statement not only points to the clones' training and construction as artists, but also presents a parallel to humanistic ideas about what a good, Enlightened man should learn - perhaps what is constructed to be deemed art? Kathy's admission reveals not only humanity's guided training on classifying by appearance, but also the clones' unnatural construction and training. Kathy and Tommy have different ways of describing his animals; while Tommy's focus is on their life forces, Kathy sees their intricate machinery. Rather than Frankenstein's creation of a larger-than-life species, Tommy's creations are miniaturized: “"The thing is, I'm doing them really small. Tiny...If you make them tiny...then everything changes. It's like they come to life by themselves. Then you have to draw in all these different details for them. You have to think about how they'd protect themselves, how they'd reach things"" (178). Rather than drawing animals dependent on intervention for animation, he sees how these animals would move and live autonomously. When Kathy sees the animals, she sees their inner machinery, rather than their inner lives, as she describes, "it took a moment to see they were animals at all. The first impression was like one you'd get if you took the back off a radio set: tiny canals, weaving tendons, miniature screws and wheels were all drawn with obsessive precision, and only when you held the page away could you see it was some kind of armadillo, say, or a bird" (187). Only when Kathy moves back from her focus on the smaller elements and parts that make up the body is she able to see the complete being.

Tommy's animals represent the struggle and back-and-forth classification of the clones that occurs throughout the novel. We can never be sure of the clones' status - are they human, with human souls and bodies, or are they machines created strictly for the 
benefit of humans? According to Shameem Black's analysis, she finds that the animals represent the humans' feelings that the clones lack souls: "Tommy's drawings of imaginary animals reveal 'the soul' to be an illusion; if we open up the animal, we find only the workings of an intricate form of machinery" (801). Many, if not most, of the humans the novel refers to consider the clones to lack souls, or, at least, human souls, and when Tommy later returns to his animals before his fourth and final donation, the animals

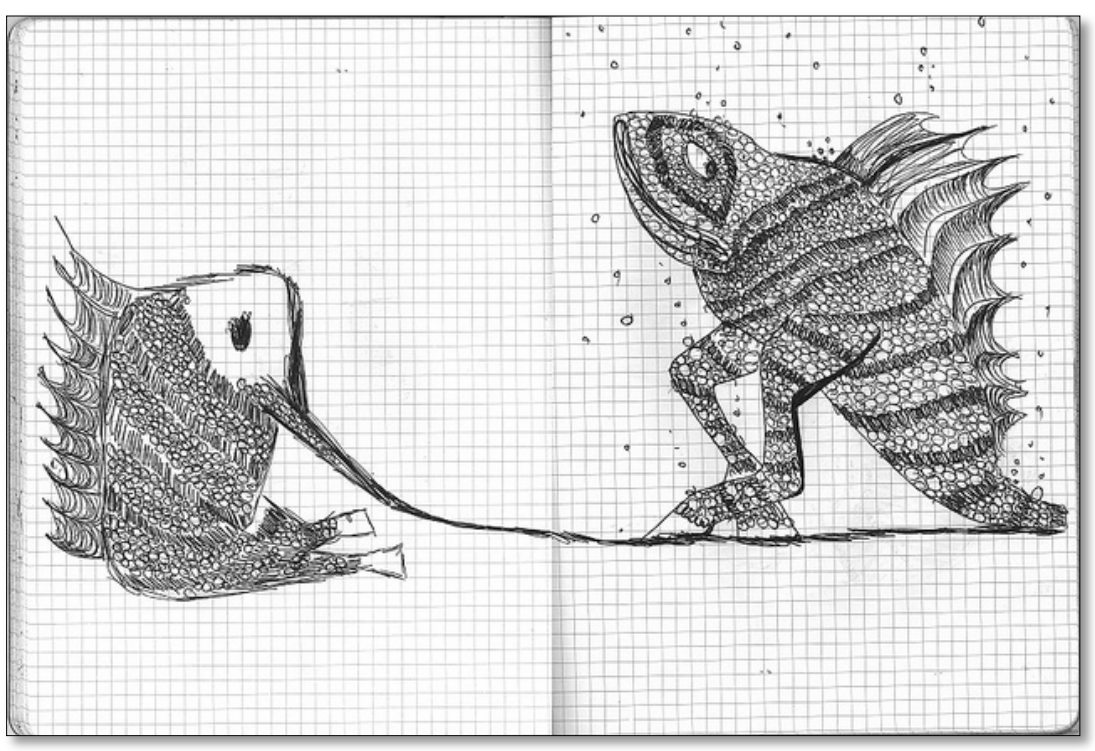

FIG. 13. Tommy's art: intermediate forms. From the 2010 film version of Never Let Me Go.

have become more explicit stand-ins for the clones' dilemma. When Kathy sees the new creatures Tommy draws, they seem to be suspended between youth and adulthood, as if they were

barred from growing any further (Fig. 13), and Tommy shows her "three separate sketches of a kind of frog - except with a long tail as though a part of it had stayed a tadpole" (241). But rather than natural and potentially able to be animated into an active life, the animals have become clones: "But something was definitely gone, and they looked laboured, almost like they'd been copied' (241 [my emphasis]). These intermediate species - stuck between body-machines almost capable of animation and copied, imitated animals - represent the barrier the clones face, caught between being 
considered fully human or an animated conglomeration of connected parts, to be disassembled when needed.

For all of the physical separation between the clones and humans, it is the shifting barrier that makes the humans fearful and uncomfortable around the clones, where the clones are both the same and different from humans. Humans can't seem to classify the clones, and this anxiety is reminiscent of the unease we see from naturalists' descriptions of human-ape hybrids, as well as Frankenstein's fears of his female creature's reproductive actions. Madame, the woman that would travel to Hailsham to collect the students' art for display in the Gallery, where humans could view the clones' artwork, always seems to be afraid of the students. As Kathy remembers, "she wouldn't talk to us and kept us at a distance with her chilly look" (32). When Ruth mentions that Madame is "scared" of them, a group of students decide to test the theory and crowd around her during one of her visits. Madame avoids touching them, and Kathy recalls how this shakes their views of how they were seen by those outside Hailsham's boundaries: "Madame was afraid of us. But she was afraid of us in the same way someone might be afraid of spiders. We hadn't been ready for that. It had never occurred to us to wonder how we would feel, being seen like that, being the spiders" (35). Kathy and her friends did not realize that they could be seen as pests, as creatures that humans don't understand and are afraid of - creatures unlike humans. Even later, when Kathy knows that they, as clones, are held to different lives than the normals, Kathy sees Madame's fear as she recognizes them as non-human: "she saw and decided in a second what we were, because you could see her stiffen - as if a pair of large spiders were set to crawl towards her" (248 [my emphasis]). But Kathy also sees something else in Madame's look this time; 
although she gave them the same look, Kathy notices that "this time there was something else, something extra in that look I couldn't fathom" (72). Madame is seeing herself in the clones, or at least her humanity - she is identifying and empathizing with the clones in their plea for continued life.

The readers, with Kathy as their narrator, are told and not told the whole truth, just as the clones are. As Rachel Carroll explains, being "told and not told" the story makes readers mimic or imitate the students' behaviors, where the clones identify and relate to humans because they are not explicitly told who, or what, they are. Several critics, including Shameem Black and John Marks, remark on the "uncanny" at work within the novel. Black points to the empathy that readers and select human characters feel for the clones, and how this allows us to move outside of the constraints of human and non-human, where we have the opportunity to see ourselves as clones because of Kathy's writing style (794). This gives the uncanny experience, which Freud defines as that which is "familiar and congenial" and yet that which is "concealed and kept out of sight" (420). Marks points out that the clones' search for their "parents," their possibles, shows them seeking out their human origins, looking for their progenitors (350). Yet Marks also discusses how the uncanny works within human cloning, and delves into a human reticence to tamper too much with "natural" reproduction: "there is a more general sense that there is something wrong about delving too deeply into biological life processes (of reproduction and development) that should properly remain hidden and unknown" (341). The clones are like us, and yet not like us. Carroll asserts that the clones' differences from humans point to precisely what makes them so uncanny, for Kathy H.'s first-person narration avoids presenting her as an Other and we then realize that we are 
identifying with a clone. This identification, when we see something of ourselves in the clones, which we may not see as part of the human species, leads us into a consideration of the ethics of the human species' treatment of non-humans. As John Marks claims, we can find certain "human" qualities in other species, and we feel "empathy for that which is irreducibly human within ourselves and others...it may be necessary to extend these feelings of empathy to encompass the aspects of our own, and other lives that, as Black puts it 'are less than fully human"” (343). Gabriele Griffin agrees with Marks's assertion, and notes that the clones' situation, with questioning what it means to be "human," "challenges conceptions of difference as absolute categories and contests the ethical imperatives underlying the insistence on such absolute difference. Instead it argues, in ethical terms...that the products of this process [biotechnological developments] therefore warrant ethical consideration in the same way as human beings or companion species" (653).

Within Never Let Me Go, Miss Emily outlines the more "political" argument that Hailsham made regarding the ethical treatment and consideration for the clones, and the humans' identification with clones becomes a large part of that argument. However, Miss Emily herself admits that she is never entirely comfortable with the clones, and does not consider them fully human, yet she felt a certain drive to fight for their lives: “We're all afraid of you. I myself had to fight back my dread of you all almost every day I was at Hailsham...But I was determined not to let such feelings stop me doing what was right"” (269). She recounts and in many ways repeats the same concerns echoed in current and previous debates about human cloning when she discusses what was happening after their war, where everyone saw how 
[s]uddenly there were all these new possibilities laid before us, all these ways to cure so many previously incurable conditions...But by the time people became concerned about...about students, by the time they came to consider just how you were reared, whether you should have been brought into existence at all, well by then it was too late. (262-3)

As with most other circumstances in the novel, we are "told and not told" about the conditions clones outside of Hailsham are subject to, but based on Miss Emily’s argument, we can assume that they were housed in facilities perhaps not unlike prisons. As she notes, "“for a long time you were kept in the shadows, and people did their best not to think about you. And if they did, they tried to convince themselves you weren't really like us. That you were less than human, so it didn't matter'" (263[my emphasis]). Hailsham was conceived to give the clones a place where they would be treated humanely and ethically, and the clones were to be given the opportunity to potentially prove that they had souls, just as humans. This would give them the consideration they deserved, at least according to the guardians: "“There, look! We could say. Look at this art! How dare you claim these children are anything less than fully human?"' (262). This identification and empathy for the clones signals the move away from a strict concern with the human / non-human divide and rather considers how the soul, human or otherwise, marks this new way of knowing, how, as Foucault reminds us, "man" as an invention and concept is coming to an end, opening up the conversation of how "human" might be more of a distinction of connection rather than classification.

\section{"HUMAN" OR HOMO SAPIENS?}

In an interview about Never Let Me Go, Ishiguro comments on the way that readers engage emotionally and empathetically with the clones. Although we somehow 
"know" or are told that the clones are not "real" humans, we identify with them and realize that their subjectivity builds into some type of relationship with our own. As Ishiguro says, "Really, it may be foolish to get all worked up emotionally about a bunch of clones, but when readers do respond emotionally, it's because they feel something exists that is real to their situation" (Wong and Crummett 217). When Kathy speaks to us as clones, she is pulling us into her point of view, and we experience and remember the world as she does, reading social codes and understanding the education into the ways of knowing humans understand as conveying and reflecting their souls. The clones, as Miss Emily admits at the end of the novel, will never be seen as completely human, and will be taken almost as Frankenstein's creature, with a fear that the clones will be the downfall of humanity: "It reminded people, reminded them of a fear they'd always had...a generation of created children who'd take their place in society? Children demonstrably superior to the rest of us? Oh no. That frightened people. They recoiled from that"' (264). The guardians' language, even Madame's constant repetition of "Poor creatures," points to the idea that the clones, through their training and education, have been conditioned throughout their lives to see themselves as less than fully human, and although they feel that they have souls, they are constantly reminded or barred from the "normal" world. This view, and the process by which humans develop standards and criteria for marking the human "difference" to non-humans, leads to the question naturalists and philosophers have been asking since the beginning of the Enlightenment period. Martin Puchner sums up the situation within Never Let Me Go when he notes, "we must ask whether it is in fact possible to establish differences between the humans and the clones apart from the fact that the clones have internalized their allegedly inferior status" (40). If the clones saw 
themselves as equal to humans, as it seems Kathy does when she asks, "Did someone think we didn't have souls?" would we be able to deny it? The realization that humans have determined a set of differences to construct a barrier between humans and nonhuman animals, even clones, exposes the "constructions" of human nature.

Just as Frankenstein's creature is denied his ability to reproduce, and Frankenstein himself worries that the female creature would be able to populate the earth with a "race of devils," the clones are created without reproductive ability. As shown in Chapter 2, the female and male creatures cannot be considered "human" because they were not created via "normal" reproduction, and the clones, without knowing their genetic parents, cannot take their place within the natural order. Frankenstein's creature and the clones may have developed souls through their educations, but none have been divinely ordained with a truly human soul. As Steve Garlick argues, there is a piece missing that would identify the "complete" human: "we easily recognize Kathy's human qualities, and yet there is an uneasy sense that something is being withheld, a secret that cannot be acknowledged, or a loss that has not fully been registered" (150-51). The clones" "non-reproductive nature" defines their non-human status (151). In Ishiguro's imagining, humans, perhaps understanding the complications from Frankenstein's own creation, pre-emptively deny the clones reproduction, but also educate the clones so that they never develop any expectations to do so. However, Kathy's dance to "Never Let Me Go," pretending to have a baby in her arms that she thought she could never have, shows us that while the creators may be able to physically bar them from having children, the human "instinct" to reproduce cannot be so easily expunged. The rumor about deferral for clones that can prove they are in love propagates this view of reproduction being crucial to being human 
- as Garlick suggests, "its [the rumor's] very existence suggests that the cloned children have an intuitive understanding that it is through the 'proper' coupling of sex and desire within a heterosexual relationship that one may gain access to the human" (151). The clones' sexual natures reminds us that they aren't fully human, but also, as Rachel Carroll explains, points to how humans have constructed their own supposedly "natural" behaviors.

When the clones learn how to perform as the normals do, with their role-playing and television mimicry, they demonstrate how they act like humans to fit in. In addition to these behaviors, Rachel Carroll, in her article "Imitations of Life: Cloning, Heterosexuality, and the Human in Kazuo Ishiguro's Never Let Me Go," argues that because the clones are performing as "humans," they are also performing normative heterosexual behavior. Since the clones can re-create human behavior, Carroll explains that what the clones (and we) see as "normal" is a construct. Carroll describes reproductive technology as both extending the masculine, patriarchal power as the "subjection of the female and maternal body" while also seeing technology as giving women bodily and reproductive agency and power (63). However, because modern technology can now move reproduction outside the female body, we can question the "natural" reproductive identity as well. This can be extended to even larger implications, because when we question the construction of the clones' reproductive identities, and we identify with the clones, we in turn question our own human identities. For the unsuspecting human, the clones are adequately "human" in appearance and demeanor that they "pass" as normals. When they enter an art gallery in Norfolk while searching for Ruth's "possible," even within close quarters, the human does not suspect their non- 
human status: "the woman was too close, much closer than we'd ever really wanted" and the gallery owner assumed they were normal, asking “Are you art students?” (163). If humans cannot tell the difference between humans and non-humans without seeing or being told their classifications, is there so much of a difference after all? When Kathy sees Tommy's creatures, composed of their various, almost mechanical parts, she does not know how to "judge" them, yet she also wants to care for them. These animals, with their inner workings and parts, are vulnerable. Even though she sees them as machines, they evoke sympathy:

I was becoming genuinely drawn to these fantastical creatures in front of me. For all their busy, metallic features, there was something sweet, even vulnerable about each of them. I remembered him telling me, in Norfolk, that he worried, even as he created them, how they'd protect themselves or be able to reach and fetch things, and looking at them now, I could feel the same sort of concerns. (188)

As Ishiguro notes, even if the clones aren't human, we identify with them and see something "real" within their situation. Foucault's shift has begun: "his closing statement that 'man,' the 'recent invention' and object of study of the social sciences, is a historically contingent construct which, with the next epistemic shift, is liable to be “erased"” (Downing 45).

Tommy's animals need care, just as the clones' carers care for them during the donation process, and we, as readers, are implicated within Kathy's world and see that the clones are worthy of human care and concern. Never Let Me Go offers a reminder that the epistemic shift is occurring, and asks, as Ishiguro himself has said, "what does it mean to be human?" The new movement, which calls human exceptionalism into question, most often labeled "posthumanism," follows one branch that asks not so much 
whether something should be classified as human, but rather whether something feels as a human. Puchner sees this shift as a call to new sympathies and consideration, arguing that "we must respond by abandoning a prior conception of what it is to be human, by imagining an ethics not exclusively based on the human," where Never Let Me Go participates in this ethics, for it "shows us that calling for an ethical treatment of a certain class of creatures does not hinge on claiming that they are, simply, humans" (47). The humans do not see the clones as fully human, but that does not stop them from calling for their ethical treatment and rights. The focus on the body and appearance has shifted to a concern for the mind or well being of a non-human. Gabriele Griffin's article, situated in both posthuman and critical feminist studies, argues that a strict opposition of the Same and Other forces an ethical reading that acknowledges the relationships between species.

Humans still have a long way to go. As Griffin argues, “[m]uch of the narrative's tension stems from this concern, the question of how much like us they actually are or can be made to be, and to what extent they are not" (654). And so, Ishiguro ends this novel in his classic style, as a sensitive and emotional relationship with a different kind of life. After Tommy completes, Kathy pulls over in an empty field and describes another barbed wire fence, and how the clones are like discarded pieces of trash. She leaves us with a reminder that the fences we construct to separate humans from non-humans may not be worth the waste:

There was a fence keeping me from stepping into the field, with two lines of barbed wire, and I could see how this fence and the cluster of three or four trees above me were the only things breaking the wind for miles. All along the fence, especially along the lower line of wire, all sorts of rubbish had caught and tangled. (287) 
The barbed wire fence's image implies barriers constructed to keep things, usually things we fear, out. However, these fences also keep their builders locked in. At the novel's close, the barrier Kathy H. contemplates suggests that the normals are as much prisoners of mindset as the clones; yet the ultimate conclusion is that these divisions and lines are rather pointless because all living beings come to the same fate - we all "complete" in the end. 


\section{CONCLUSION}

The understanding that develops throughout Never Let Me Go conveys a shift in consideration and empathy for non-humans, and represents a considerable departure from Enlightenment texts that rely on appearance and taxonomic nomenclature to define a species. As many new works during this period of time have shown the end of the period Foucault classifies as the "invention of "man," humans seem to be more willing to care for non-humans as well as their own fellow-creatures. Works such as J.M. Coetzee's Disgrace present human characters that experience, or at least can imagine, the point of view of those Other than themselves, whether a different race, gender, or species. When humans can identify and empathize with another, they begin to reconsider previously held notions of superiority.

Eighteenth-century naturalists' texts relied on eyewitness accounts, and were susceptible to the dangers of creating inaccurate and sometimes false reports of humanape hybrids. These documents, and their accompanying images, often tell a narrative of human/non-human relationships that were dangerous suggestions of humans creating creatures that would defy the barrier that regulated the divine human and base animal. Not only were Western European men afraid that there were non-humans, potentially thinking non-humans, in undeveloped and wild lands, but they were also afraid that these beings could overturn the Biblical narrative that ascribed all naming power to Adam. If 
there were other types of humans, in the wild, then the claims to superiority would be in jeopardy. Although science began to seek natural explanations for previously perceived "miraculous" phenomena, naturalists and others still maintained that humans were special in the eyes of their Creator. This belief brought about numerous symbols of human exceptionalism, including the Great Chain of Being and Cartesian animal-machines. Lord Monboddo's claims of human language and social development determined that there was a progression of a species from a simple to more complex form. Of course, this theory and others were modified to form Charles Darwin's On the Origin of Species, but Darwin's theories of natural selection and descent also allowed for human development and improvement. Darwin's work posits that humans are susceptible to the same biological and social factors of adaptation and selection as the so-named "lower" animals. However, even though most scientists now adhere to the assertion that humans are animals, just like other beings, they continue to search for new ways to prove that humans are "different" and superior.

After the Enlightenment period in England, when colonization and development began in earnest, many more members of the public became particularly interested in the "progress" of native peoples in faraway lands. The images reproduced in this thesis present the power of the "gaze" and the power that the European lens held over what was communicated about the human Other. Just as specimens of apes were brought to Europe for live study, so too were humans, and power relations were strictly controlled by the presentation and narrative therein. Native peoples were "lower" humans and needed to be civilized, but how could eighteenth and nineteenth-century naturalists convince their European public? Harriet Ritvo explains that exhibitions and traveling shows produced a 
visual record of documentation, showing as well as telling Europeans that they were in the position of power and responsibility, for "Museums frequently displayed the remains of non-European beings in ways that underlined their difference from Europeans or suggested their greater affinity with other animals" (Platypus 125). However, live "specimens" were often displayed; as Annie E. Coombes describes in her book, Reinventing Africa, the growing exhibition and colonial tourism practices of the late eighteenth and nineteenth centuries brought African flora and fauna, including humans, to life on a grand scale, presenting humans in their "native" settings for the gaze of Europeans in a simulacrum of their "real" lives. The power of the Panoptic gaze existed there, for the native peoples were placed in settings such as villages and houses, forced to live in these homes as if they were simply moved rather than completely displaced. They were, in all purposes, "induce[d] in...a state of conscious and permanent visibility that assures the automatic functioning of power" (Foucault, Discipline 554). The power of the gaze becomes internalized and invisible, so much so that the natives could not distinguish their previous existence to the present, or so was claimed by Europeans, where a "frequent feature of this discourse is the claim that the verisimilitude of the scene is so complete that the occupants themselves fail to recognise that they are living in a simulated environment" (Coombes 88). Being on display and visible at all times forced the native peoples into a type of incarcerated apathy, and, as suggested by Foucault, a major function of power-knowledge relations: "He who is subjected to a field of visibility...assumes responsibility for the constraints of power, he makes them play spontaneously upon himself, he inscribes in himself the power relation in which he simultaneously plays both roles" (Discipline 555-6). According to this logic, Europeans 
used Africans' perceived acceptance of this power dynamic as a way to justify their civilizing efforts, and also their treatment of native men and women.

By investigating texts such as Frankenstein and Never Let Me Go in concert with locating the origins and practice of the classifying discourse that became so integral to the way that Western humans have learned to understand and order the world around them, we can understand how our subject positions form the basis of our treatment of humans and non-humans alike. To return to Annette Kolodny's ideas, literature aims to locate social codes and ideologies, and either comment, resist, or reaffirm those values. In a world where humans are subject to scientific inquiry just as all other animals, the Western notions of being civilized and genteel human beings help people maintain the ideal of human difference. The discourse that developed during the Enlightenment became the dominant way to think and know about the world, and so any creature that defied the boundaries established therein was subversive and dangerous. As I have shown, Mary Shelley resists this strict classification, and creates a creature that seems to exist on both sides of the barrier. The creature, as a new species, and one that is superior in many ways, frightens us because it means that something else can stand between the human and the divine, and if it had a soul, it could remove the human "difference." Hailsham's clones also occupy the dividing line, and reflect back to us what it means to be human.

From ideas of human "progress" to questions of what makes humans unique, the tradition of hierarchical categorization with humans at the top of the Great Chain of Being involves interdisciplinary avenues, including science, philosophy, religious studies, and the humanities, including literature and art. Although literature has been the main focus of this thesis, the question of how the previously established notions of the human 
"difference" are evolving, perhaps back to an investigation of similarity, spans across the disciplines and discourse traditions. However, as science becomes more and more anticorporeal, more of a text rather than a body, the focus on affinity and difference may once again shift back to an "us" versus "them" mentality, especially given that many populations are once again becoming Other, without access or knowledge of the new emerging technological discourse. And just as we understand Kathy and the creature's texts, we must allow for numerous ways of knowing the human condition, and understand that the distinction of being classified as Homo sapiens might not be the only consideration for humanity and the humane. 


\section{REFERENCES}

Anderson, Lorin. "Charles Bonnet's Taxonomy and Chain of Being." Journal of the History of Ideas 37.1 (1976): 45-58. Print.

Armstrong, Nancy. "Some Call It Fiction: On the Politics of Domesticity." Literary Theory: An Anthology. Ed. Julie Rivkin and Michael Ryan. 2nd ed. Malden: Blackwell, 2004. 567-83. Print.

Barbour, Judith. "The Professor and the Orang-Outang: Mary Shelley as a Child Reader." Frankenstein's Science: Experimentation and Discovery in Romantic Culture, 1780-1830. Ed. Christa Knellwolf and Jane Goodall. Surrey: Ashgate, 2008. 3348. Print.

Barnard, Alan. "Orang Outang and the Definition of Man: The Legacy of Lord Monboddo." Fieldwork and Footnotes: Studies in the History of European Anthropology. Ed. Han F. Vermeulen and Arturo Alvarez Roldán. London: Routledge, 1995. 95-112. Print.

Bernatchez, Josh. "Monstrosity, Suffering, Subjectivity, and Sympathetic Community in 'Frankenstein' and 'the Structure of Torture'." Science Fiction Studies 36.2 (2009): 205-16. Print.

Bewell, Alan. "An Issue of Monstrous Desire: Frankenstein and Obstetrics." The Yale Journal of Criticism 2 (1988): 105-28. Print. 
Black, Shameem. "Ishiguro's Inhuman Aesthetics." Modern Fiction Studies 55.4 (2009): 785-807. Print.

Bonnet, Charles. Traité D'insectologie. Vol. 1. A Paris: Chez Durand, 1745. Web. 5 Feb. 2013.

Brandt, Mark J. and Christine Reyna. "The Chain of Being: A Hierarchy of Morality." Perspectives of Psychological Science 6.5 (2011): 428-46. Print.

Brantlinger, Patrick. Taming Cannibals: Race and the Victorians. Ithaca: Cornell UP, 2011. Print.

Britzman, Deborah P. "On Being a Slow Reader: Psychoanalytic Reading Problems in Ishiguro's Never Let Me Go." Changing English 13.3 (2006): 307-18. Print.

Brooks, Peter. "What Is a Monster? (According to Frankenstein)." Frankenstein: A Norton Critical Edition. Ed. J. Paul Hunter. 2nd ed. New York: WW Norton \& Company, 2012. 368-90. Print.

Buffon, George Louis Leclerc. Natural History: General and Particular. Trans. William Smellie. 3rd ed. Vol. 8: A. Strahan, 1791. Print.

Burke, John C. "The Wild Man's Pedigree: Scientific Method and Racial Anthropology." The Wild Man Within: An Image in Western Thought from the Renaissance to Romanticism. Ed. Edward Dudley and Maximillian E. Novak. Pittsburgh: U Pittsburgh Press, 1972. 259-80. Print.

Burney, Frances. Evelina. Bedford Cultural Editions. Ed. Kristina Straub. Boston: Bedford, 1997. Print.

Carroll, Rachel. "Imitations of Life: Cloning, Heterosexuality, and the Human in Kazuo Ishiguro's Never Let Me Go." Journal of Gender Studies 19.1 (2010): 59-71. Print. 
Castle, Terry. The Female Thermometer: Eighteenth-Century Culture and the Invention of the Uncanny. New York: Oxford UP, 1995. Print.

Chevalier, W. Frankenstein Observing the First Sitrrings of His Creature. 1831. H. Colburn and R. Bentley, London. Wellcome Library. Web. 27 March 2013.

Cloyd, E.L. James Burnett, Lord Monboddo. Oxford: Clarendon, 1972. Print.

Coetzee, J.M. Disgrace. First ed. New York: Viking, 1999. Print.

Coombes, Annie E. Reinventing Africa: Museums, Material Culture and Popular Imagination in Late Victorian and Edwardian England. New Haven: Yale UP, 1994. Print.

Darwin, Charles. The Voyage of the Beagle: Journal of Researches into the Natural History and Geology of the Countries Visited During the Voyage of the H.M.S. Beagle Round the World. New York: Modern Library, 2001. Print.

Douthwaite, Julia V. The Wild Girl, Natural Man, and the Monster: Dangerous Experiments in the Age of Enlightenment. Chicago: U of Chicago, 2002. Print.

Downing, Lisa. The Cambridge Introduction to Michel Foucault. Cambridge: Cambridge UP, 2008. Print.

Engelstein, Stefani. Anxious Anatomy: The Conception of the Human Form in Literary and Naturalist Discourse. Studies in the Long Nineteenth Century. Ed. Pamela K. Gilbert. Albany, NY: SUNY Press, 2008. Print.

Fara, Patricia. "Educating Mary: Women and Scientific Literature in the Early Nineteenth Century." Frankenstein's Science: Experimentation and Discovery in Romantic Culture, 1780-1830. Ed. Christa Knellwolf and Jane Goodall. Surrey: Ashgate, 2008. 17-32. Print. 
Favret, Mary A. "A Woman Writes the Fiction of Science: The Body in Frankenstein." Genders 14 (1992): 50-65. Print.

Fitzroy, Robert. The Narrative of the Voyages of H.M. Ships Adventure and Beagle:

Proceedings of the Second Expedition, 1831-36. London: Henry Colburn, 1839. Web. 14 Nov. 2012.

Foucault, Michel. "Discipline and Punish." Literary Theory: An Anthology. Ed. Julie Rivkin and Michael Ryan. 2nd ed. Malden: Blackwell, 2004. 549-66. Print. ---. The Order of Things: An Archaeology of the Human Sciences. New York: Random House, 1994. Print.

Freeman, John. "Never Let Me Go: A Profile of Kazuo Ishiguro." Conversations with Kazuo Ishiguro. Ed. Brian W. Wong and Cynthia F. Shaffer. Jackson, MS: UP of Mississippi, 2008. 194-98. Print.

Garlick, Steve. "Uncanny Sex: Cloning, Photographic Vision, and the Reproduction of Nature." Social Semiotics 20.2 (2010): 139-54. Print.

Goldner, Ellen J. "Monstrous Body, Tortured Soul: Frankenstein and the Juncture between Discourses." Genealogy and Literature. Ed. Lee Quinby. Minneapolis, MN: U Minnesota Press, 1995. 28-47. Print.

Greenfield, Susan C. "Monkeying around in Evelina: Identity and Resemblance Again." The Eighteenth-Century Novel 6-7 (2009): 409-28. Print.

Griffin, Gabriele. "Science and the Cultural Imaginary: The Case of Kazuo Ishiguro's Never Let Me Go." Textual Practice 23.4 (2009): 645-63. Print.

Halberstam, Judith. Skin Shows: Gothic Horror and the Technology of Monsters. Durham, NC: Duke UP, 1995. Print. 
Hamilton, Patricia. "Monkey Business: Lord Orville and the Limits of Politeness in Frances Burney's Evelina." Eighteenth-Century Fiction 19.4 (2007): 415-40. Print. Haraway, Donna J. "In the Beginning Was the Word: The Genesis of Biological Theory." Signs 6.3 (1981): 469-81. Print.

Hunnewell, Susannah. "Kazuo Ishiguro, the Art of Fiction No. 196." The Paris Review 184 (2008). Web.

Ishiguro, Kazuo. Never Let Me Go. New York: Vintage, 2006. Print.

Jacobus, Mary. "Is There a Woman in This Text?" Reading Women: Essays in Feminist Criticism. New York: Columbia UP, 1986. 83-109. Print.

James, Nick. "The Art of Letting Go." Sight \& Sound 21.3 (2011): 39. Print.

Knellwolf, Christa, and Jane Goodall. "Introduction." Frankenstein's Science: Experimentation and Discovery in Romantic Culture, 1780-1830. Ed. Christa Knellwolf and Jane Goodall. Surrey: Ashgate, 2008. 1-16. Print.

Koelb, Clayton. "'I Sickened as I Read': Mary Shelley's Frankenstein." The Revivifying Word: Literature, Philosophy, and the Theory of Life in Europe's Romantic Age. Studies in German Literature, Linguistics, and Culture. Rochester, NY: Camden House, 2008. 127-44. Print.

---. "Introduction: 'The Dead Man's Life': Romantic Reading and Revivification." The Revivifying Word: Literature, Philosophy, and the Theory of Life in Europe's Romantic Age. Studies in German Literature, Linguistics, and Culture. Rochester, NY: Camden House, 2008. 3-13. Print. 
Kolodny, Annette. "Dancing through the Minefield: Some Observations on the Theory, Practice, and Politics of a Feminist Literary Criticism." Feminist Studies 6.1 (1980): 1-25. Print.

Liebman, Elizabeth Amy. "Animal Attitudes: Motion and Emotion in Eighteenth-Century Animal Representation." Journal for Eighteenth-Century Studies 33.4 (2010): 663-83. Print.

Marks, John. "Clone Stories: 'Shallow Are the Souls That Have Forgotten How to Shudder'." Paragraph 33.3 (2010): 331-53.Print.

McClintock, Anne. "The Angel of Progress: Pitfalls of the Term 'Post-Colonialism'." Social Text 31-32 (1992): 84-98. Print.

McDonald, Keith. "Days of Past Futures: Kazuo Ishiguro's Never Let Me Go as 'Speculative Memoir'." Biography 30.1 (2007): 74-83. Print.

Meijer, Miriam Claude. Race and Aesthetics in the Anthropology of Petrus Camper. Studies in the History of Ideas in the Low Countries. Ed. Hans W. Blom, Henri Krop, Wijnand W. Miljnhardt, and Siep Stuurman. Amsterdam: Rodopi, 1999. Print.

"Never Let Me Go: Folio Illustrated Book." The Folio Society. Folio Society, 2013. Web. 27 March 2013.

“Never Let Me Go: Tommy’s Drawing.” Movielicious! Blogger.com, 26 Aug. 2010. Web. 27 March 2013.

Novak, Maximillian E. "The Wild Man Comes to Tea." The Wild Man Within: An Image in Western Thought from the Renaissance to Romanticism. Ed. Edward Dudley and Maximillian E. Novak. Pittsburgh: U Pittsburgh Press, 1972. 183-221. Print. 
Peacay."Mongrel.” BibliOdyssey. Blogspot, 10 May 2010. Web. 28 Oct. 2012.

Pepys, Samuel. The Diary of Samuel Pepys M.A. F.R.S. Vol. 2. London: George Bell \& Sons, 1893. Web. 17 Oct. 2012.

Puchner, Martin. "When We Were Clones." Raritan 27.4 (2008): 34-49. Print.

Riskin, Jessica. "The Defecating Duck, or, the Ambiguous Origins of Artificial Life." Critical Inquiry 29.4 (2003): 599-633. Print.

Ritvo, Harriet. "Border Trouble: Shifting the Line between People and Other Animals." Social Research 62.3 (1995): 481-500. Print.

---. The Platypus and the Mermaid and Other Figments of the Classifying Imagination. Cambridge: Harvard UP, 1997. Print.

Rodis-Lewis, Geneviève. "Limitations of the Mechanical Model in the Cartesian Conception of the Organism." Descartes: Critical and Interpretive Essays. Ed. Michael Hooker. Baltimore: John Hopkins UP, 1978. 152-70. Print.

Roger, Jacques. Buffon: A Life in Natural History. Trans. Sarah Lucille Bonnefoi. Ithaca: Cornell UP, 1997. Print.

Schiebinger, Londa. Nature's Body: Gender in the Making of Modern Science. Boston: Beacon Press, 1993. Print.

de Sève, Jacques. Le Jocko. 1749-1804. Imprimerie Royale, Paris. Wellcome Library. Web. 18 Sept 2012.

Shelley, Mary. Frankenstein: A Norton Critical Edition. Ed. J. Paul Hunter. New York: WW Norton, 2012. Print. 
Stern, Megan. "Dystopian Anxieties Versus Utopian Ideals: Medicine from Frankenstein to the Visible Human Project and Body Worlds." Science as Culture 15.1 (2006): 61-84. Print.

Tanjé, P. Carolus Linnaeus. 1778. Wellcome Library. Web. 7 Nov. 2012.

Types of "primitive" man as imagined by $17^{\text {th }}$ century anthropologists. 1. Troglodyta

Bontii. 2. Lucifer Aldrovandi 3. Satyrus Tulipii 4. Pygmaeus Edwardi. 1760. Wellcome Library. Web. 24 Sept. 2012.

Waldby, Catherine. "The Instruments of Life: Frankenstein and Cyberculture." Prefiguring Cyberculture: An Intellectual History. Ed. Darren Tofts, Annemarie Jonson, and Alessio Cavallaro. Cambridge, MA: MIT, 2002. 28-37. Print.

Wilson, Deborah S. "Technologies of Misogyny: The Transparent Material Body and Alternate Reproductions in Frankenstein, Dracula, and Some Selected Media Discourses." Bodily Discursions: Genders, Representations, Technologies. Ed. Deborah Wilson and Christine Moneera Laennec. Albany, NY: State U of New York Press, 1997. 105-33. Print.

Wong, Cynthia F. and Grace Crummett. "A Conversation About Life and Art with Kazuo Ishiguro." Conversations with Kazuo Ishiguro. Ed. Brian W. Wong and Cynthia F. Shaffer. Jackson, MS: UP of Mississippi, 2008. 204-20. Print.

Zakharieva, Bouriana. "Frankenstein of the Nineties: The Composite Body." Frankenstein. Boston: Bedford/St. Martin's, 2000. 416-31. Print. 


\section{CURRICULUM VITAE}

\section{Emily Regina Freund emily.freund@louisville.edu emilyfreund@gmail.com}

\section{Education:}

University of Louisville, Louisville, Kentucky

Master of Arts, English

Graduated May 2013

Thesis: "'Two Machines Similarly Constructed': Humanity Between Apes and

Clones"

Indiana University, Bloomington, Indiana

Bachelor of Arts, English \& Anthropology

Graduated May 2003

\section{Awards:}

Red \& Black Scholar-Athlete Mentor Award

University of Louisville 2013

Mary Elizabeth Campbell Book Award for Excellence in English Indiana University 2002

\section{Professional Societies:}

Phi Beta Kappa, Indiana University

\section{National Meeting Presentations:}

"Creating New Writing Center Identities: A Close Reading"

Paper presented at the National Conference of Peer Tutors in Writing

\section{Symposia:}

"Let the Fun Begin: Pee-Wee's Postmodern Playhouse"

Paper presented at the Graduate Student Research Symposium

\section{Teaching Experience:}

English 101 - Introduction to College Writing English 102 - Intermediate College Writing (Research) 